\title{
External Shocks and the Adequacy of Foreign Reserves: The Case of Mexico*
}

\author{
Salem Nechi ${ }^{\dagger}$
}

January 2009

\section{Job Market Paper}

\begin{abstract}
Recent research highlights the presence of significant increases in reserves accumulated by emerging market economies in the last decade and half. This is often viewed as the result of deliberated policies by governments wishing to insure themselves against the risk of balance of payments (hereafter, BOP) crises. Using Mexico as an example, this paper (i) explores the relative importance of external shocks as key determinants of the increase of foreign reserves accumulated since the 1990s, (ii) generates an empirical method aimed at assessing the adequacy of reserve holdings, and (iii) predicts BOP crises forced by external shocks. Using the returns on a set of international financial securities and oil variables to identify exogenous shocks to Mexico, I decompose foreign reserves into those driven by external shocks and those driven by policy targets. I argue that foreign reserves can be approximated as stationary functions of external shocks. In particular, I find that about $70 \%$ of the variation in foreign reserves can be replicated by a linear combination of the external shocks. Taking into account the effects of the exogenous shocks on reserves buildup, I develop a new approach to evaluate the adequacy of reserves policy, based on a concept of BOP sustainability that can accommodate a variety of future policy patterns, and allows the stock of reserves to influence the likelihood of BOP crises. According to this approach, aside from 1994, historically Mexico held an adequate level of reserves. However, although the reserves policy in place is adequate (i.e., effective) in the short run, a BOP crisis is more likely in the long run.
\end{abstract}

JEL Classification: F31, F34, F37, G12, G15.

Keywords: Foreign Reserves, Reserves Target, External Shocks, Sustainability, Adequacy.

*I am grateful to Huw Lloyd-Ellis and Thorsten Koeppl for their enormous helpful comments and feedback. I also thank Beverly Lapham, Sharon Kozicky, Mario Crucini, Katsumi Shimotsu, Morten Nielsen and seminar participants at Queens University, Midwest Economics Association Meeting 2008, the Canadian Economics Association Meeting 2008, the Small Open Economies in Globalized World Conference in Waterloo 2008.

†PhD Candidate, Department of Economics, Queen's University. 94 University Avenue, Kingston, Ontario, Canada K7L 3N6. Phone: +1 6135336000 ext. 75540. Fax: +1 613533 6668. E-mail: nechis@econ.queensu.ca 


\section{Introduction}

Recent research highlights the presence of significant increases in reserves accumulated by emerging market economies in the last decade and half. ${ }^{1}$ This is often viewed as the result of deliberated policies by governments wishing to insure themselves against the risk of BOP crises, ${ }^{2}$ which were perceived as more likely and more severe after the 1990s financial crises. To a large extent, however, existing analyzes of foreign reserves pay little attention to the effects of external shocks on reserves build up. To address this question, some authors have investigated the role of "external factors"-U.S interest rates and other indicators such as income, real estate and equity markets-as a source of volatility of the real exchange rate and foreign exchange in many countries (See for example Calvo et al., 1993). However, the analysis fails to separate out movements in foreign reserves that are due to external shocks from those resulting from permanent shift in reserves policy. The question of how much foreign reserves the policymaker should hold to mitigate these shocks is also left unanswered.

This paper explores the relative importance of external shocks as key determinants of the significant increase of foreign reserves accumulated by Mexico, and generates a simple and tractable empirical method aimed at assessing the adequacy of reserve holdings and predicting BOP crises forced by external shocks. To this end, I propose a decomposition method that emphasizes the contribution of exogenous factors to reserves accumulation. Subsequently, I characterize the response of reserves policy to these shocks and show to what extend reserves can mitigate the adverse consequences of external influences. Using an asset pricing model for calibration, I find that the model can match quite closely the historical episodes of BOP in Mexico. Finally, I produce a prediction of financial crisis based on a new concept of BOP sustainability that allows the stock of reserves to influence the likelihood of crises. Mexico provides a good example for our analysis for several reasons. Among them are: (a) its financial and trade integration has intensified since the mid-1980s, which makes it more vulnerable to exogenous shocks, (b) its international reserves stock has increased in the aftermath of the Tequila crisis, and (c) since Mexico is a small open economy, it is much easier to identify shocks that are clearly exogenous to the Mexican economy.

The paper is built around a model in which the policymaker adopts a target level of reserves to GDP (i.e., permanent component) and reserves accumulated evolve around that target. Reserves process is driven by a set of unobservable variables. I use the returns on a set of international financial securities and oil variables to identify exogenous shocks to the components of Mexico's reserves. I argue that movements in reserves can be replicated by a simple linear combination of external shocks. In particular, I find that external shocks account for $70 \%$ of the variation in foreign reserves. Because external shocks to the economy turn out to account for so much variation in foreign reserves, the effectiveness of foreign reserves as buffer stock to insure against future BOP crises becomes a key issue. In fact, considering reserves policy

\footnotetext{
${ }^{1}$ Durda, Mendoza, and Terrones (2007) surveyed 17 countries hit by the financial crises during the last decade and half and found that the median increase in reserve holdings in these countries is 7.7 percent of GDP (measured as the cross-country median of the differences between each country's average reserves-to-GDP ratio from the year of the country's Sudden Stop to 2004 and the average from 1985 to the year of the Sudden Stop). See table 1 in their paper.

${ }^{2}$ According to a survey of central bankers of developing and emerging market countries, the main reason for the recent buildup in reserves was to "secure protection from volatile capital flows". See Pringle and Carver (2005).
} 
as a tool to cop with liquidity shortage in times of a crisis while they (reserves) are not fully controlled by monetary authorities (since they are driven by external factors) might result in ineffective intervention. Taking into account the effects of external shocks, I develop a new approach to assessing the adequacy of reserves holdings. My approach is based on Melesi-Ferri and Razin (1996) sustainability condition, but extended to allow the reserves to influence the likelihood of BOP crises. I am essentially comparing the stock of reserves accumulated plus the present discounted value of trade balance to the net liability position of the economy. The overall analysis suggests that, apart from 1994, historically Mexico has satisfied its external sustainability condition. But, going forward, the probability of unsustainability in the near future is quite high.

The paper is part of a growing literature on large international reserve holdings by emerging market economies in recent years. ${ }^{3}$ The existent studies claim that this accumulation is motivated by a large precautionary demand, providing self-insurance against the adverse output effects of sudden stops and capital flight shocks. For instance, Aizenman and Marion (2003), Bird and Rajan (2003), Aizenman, Lee, and Rhee (2004), Gosselin and parent (2005), Aizenman and Lee (2005), Jeanne (2007), and Cheung and Ito (2007) argue that developing countries opted for new policy in the aftermath of 1990s crises consisting in accumulating international reserves. This argument is based on econometric evaluations suggesting several structural changes in the patterns of reserves hoarded by developing countries. ${ }^{4}$ These studies have typically considered the variability of international receipts and payments as key determinant of the demand for foreign reserves. Against this background, there has been surprisingly little work trying to quantify the importance of external shocks on reserves buildup.

I am not the first to emphasize the importance of external shocks on foreign reserves, though. Mollick (2002) searches for responses of the real exchange rate and reserves in Mexico to shocks in U.S. interest rates (and to the Mexican M2/Reserves ratio) over the years 1988-2001. He finds that shocks to U.S. interest rates explain not more than $7.4 \%$ of the variance of international reserves and only $5.5 \%$ of real exchange rate changes. Calvo et al. (1993) show that foreign components of U.S. interest rates and other indicators (income, real estate and equity markets) are able to explain around $50 \%$ of the variance of the real exchange rate and foreign exchange reserves in ten Latin American economies. Levy and Sturzenegger (2000) claim that the European business cycle (German interest rates) affects foreign exchange reserves and the real exchange rate in several Latin American economies during the early 90s, replicating the conjecture to Europe.

A key novelty of my analysis is that I identify exogenous shocks to Mexico to separate out the movements in foreign reserves that are due to exogenous factors from those resulting from permanent shifts in policy. In addition to being exogenous with respect to Mexico's financial policy, I find that these variables explain

\footnotetext{
${ }^{3}$ The dramatic hoarding of international reserves was lopsided: while the International reserves-GDP ratios of industrial countries was overall stable, hovering around 4\%, the reserves-GDP ratios of developing countries increased dramatically, from about $5 \%$ in 1990 to about $27 \%$ in 2006 .

${ }^{4} \mathrm{~A}$ notable change occurred in the 1990s, a decade when the international reserves/GDP ratios shifted upwards; a trend that intensified shortly after the Mexican crisis of 1994 and the East Asian crisis of 1997-8, but subsided by 2000 . Another structural change have taken place in early 2000s, mostly driven by an unprecedented increase in the hoarding of international reserves in China, from close to zero during 1998-2000 to more than $\$ 300$ billion in 2006.
} 
a large portion of the variation in foreign reserves movements than the variables traditionally used in the literature-capital and current accounts variables. ${ }^{5}$ The growing self-insurance argument together with the strong and stable correlation between the external shocks and foreign reserves motive the need for an assessment rule of reserves adequacy that accounts for the effect of external shocks on reserves buildup and allows the stock of reserves to influence the likelihood of BOP crises. The empirical method I develop in section 3 is one step in this direction. According to this method, a reserve target (i.e., policy) is adequate if the probability of BOP crisis over a given time horizon is sufficiently low.

Traditionally the adequacy of foreign reserves is done using rules of thumb. ${ }^{6}$ The ratio of reserves to short-term external debt measures the capacity of a country to service its external liabilities in the forthcoming year, should external financing conditions deteriorate sharply. According to the GreenspanGuidotti rule, a ratio above one signals that a country holds an adequate level of reserves to face the risk of a financial crisis, while a ratio below one may suggest a vulnerable capital account. ${ }^{7}$ The ratio of reserves to imports is considered as a proxy for a country's current account vulnerability. The ratio measures the number of months a country is able to finance its current level of imports. Normally, a ratio of 3 and 4 would be considered adequate (Fisher 2001). ${ }^{8}$ Lastly, an indicator that is commonly used is the ratio of reserves to broad money. A conventional range for the ratio of reserves to broad money is 5 to 20 percent. The rationale for this ratio is that broad money reflects a country's exposure to the withdrawal of assets from domestic sources(Calvo, 1996; De Beaufort-Wijnholds, Onno, and Kapteyn, 2001). Although these ratios provide a good measure of reserves adequacy in terms of a country's resiliency when facing a potential financial crisis, they abstract from key determinants of an economy sustainability, ignore the dynamics of the BOP, and do not provide a comprehensive framework for policy evaluation purposes.

The approach taken here is similar to that of Lloyd-Ellis and Zhu (2001, 2006) who investigate the large and persistent budget surplus in Canada during the 1980s and 1990s and use internationally traded asset returns as instruments to identify exogenous shocks to surplus. They decompose movements in the primary surplus into those resulting from exogenous shocks and those induced by significant shifts in fiscal stance. Their results show that two thirds of the variation in the primary surplus can be replicated by a simple linear combination of the asset returns.

The remainder of the paper proceeds as follows. Section 2 exposes the decomposition method as well as the empirical model and results. In section 3, I propose a new approach to assess the adequacy of foreign reserves holdings and present the estimates of the trade balance. Section 4 describes how to use a calibrated asset pricing model to compute the present value of the trade balance, and discuss the adequacy of the Mexican policies. Concluding remarks are provided in section 5. Details regarding the data, our calibration methodology, market valuation of trade balance, and simulation algorithm are provided in the appendix.

\footnotetext{
${ }^{5}$ See for example, Heller and Khan 1978; Edwards 1985; Lizondo and Mathieson 1987; Landell-Mills 1989; Lane and Burke 2001, IMF 2003, Gosselin and Parent 2005; among others

${ }^{6}$ See Bird and Rajan (2003) for a discussion

${ }^{7}$ See Greenspan (1999) and BIS (2000).

${ }^{8}$ The ratio of reserves to imports should equal 0.25 according to the three-months-of-imports rule.
} 


\section{External Shocks and Reserves Accumulation}

Mexico experienced a significant increase in its foreign reserves holdings in the aftermath of the Tequila crisis. The purpose of this section is to determine how much of the increase in reserves can be explained by permanent shift in "reserves policy" and how much can be attributed to external influences.

\subsection{Decomposition of Foreign Reserves}

Here, I propose a decomposition method that separates movements in foreign reserves that are attributed to external influences from parts attributed to significant shifts in "policy". To do so, I assume that the policymaker adopts a target ratio of reserves to GDP, $R_{t}^{*}$, and reserves evolve as follow

$$
\frac{R_{t}}{Y_{t}}=R_{t}^{*} e^{F\left(Z_{t}\right)}
$$

or,

$$
\ln \left(\frac{R_{t}}{Y_{t}}\right)=\Gamma_{t}+F\left(Z_{t}\right) .
$$

where $\Gamma=\ln \left(R_{t}^{*}\right)$, and $Z_{t}$ is the vector that summarizes the exogenous shocks in period $t$. The term $\Gamma_{t}$ is a key component in my analysis. It summarizes the permanent components of the government's policy variables. It could be time-varying and may change in response to the debt level and political events. In other words, it represents the non-shock related components of foreign reserves. I interpret significant and persistent changes in $\Gamma$ as being associated with changes in the central bank's reserves policy (i.e., target ratio of reserves to GDP). $F\left(Z_{t}\right)$ represents components of the reserves that are shock-related.

In general, the state vector $Z_{t}$ may contain variables that are difficult to identify or not directly observable. Let $X_{t}$ be a vector of observable variables that are correlated with the state vector $Z_{t}$. Using linear approximation, I can express $F_{t}\left(Z_{t}\right)$ as follows:

$$
F_{t}\left(Z_{t}\right)=\beta^{\prime} X_{t}+\epsilon_{t}
$$

where $\epsilon_{t}$ is the residual that represents the shocks that are not captured by the observable variables. The vector $\beta$ measures the marginal impact of the exogenous shocks. Thus, the reserves process can be expressed as

$$
\ln \left(\frac{R_{t}}{Y_{t}}\right)=\Gamma_{t}+\beta^{\prime} X_{t}+\epsilon_{t}
$$

This representation captures the variation of reserves resulting from exogenous shocks and parts driven by the policy target. ${ }^{9}$

\footnotetext{
${ }^{9}$ In general policymakers might respond to exogenous shocks by adjusting reserves holdings. This raises the question of whether the policy target is independent from the exogenous shocks. To expose this issue further, another way to represent (2) is

$$
\ln \left(\frac{R_{t}}{Y_{t}}\right)=\underbrace{\Gamma+\bar{\beta}^{\prime} X_{t}}_{\text {Policy }}+\beta^{\prime} X_{t}+\epsilon_{t},
$$
}


So, the first step in our decomposition method is to identify the vector of observable variables, $X_{t}$. Once these variables are identified, we can then use regression to estimate the shock dependence vector $\beta$ and the policy component, $\Gamma_{t}$.

\subsection{Empirical Analysis}

I use quarterly foreign reserves data for Mexico over the 1981:Q1 to 2006:Q4 sample period. For the explanatory variables, I revisit the variables commonly used in the literature, traditional variables, and introduce a set of new variables that I consider key to my analysis, shock variables. The traditional variables which represent the case when the variables in $X_{t}$ are identified to capture the variability of international receipts and payments. They consist mainly of current and capital accounts variables. I introduce these variables to compare my results with the findings of previous studies. The data for this set of variables span from 1985:Q4 to 2006:Q4. I consider imports propensity LIMP (log of imports to GDP); broad money LM2 (log of M2 to GDP); exports volatility EXPV (10 quarters backward moving standard deviation of exports receipts); financial openness FO (ratio of capital flows to GDP); the exchange rate volatility EXRV (12 months backward moving standard deviation of end-of-period exchange rate); and the opportunity cost of holding reserves, OPPCOST, (measured as the domestic lending rate minus the U.S treasury bill rate).

The exogenous shock variables consist of indices of the market returns on a set of internationally traded financial assets and oil variables. I use these variables to identify shocks to foreign reserves. The data for this set of variables span over the same period as the dependent variable. The asset return variables are the value weighted return (excluding dividend) on the New York Stock Exchanges, VWR (from the CRSP tape), the dividend yield, DIV, on the CRSP value-weighted index (measured as a 1-year backward moving average of dividends divided by the S\&P500 Composite Price Index-stock market price index at the first month of the quarter), the 3-month Treasury bill rate TBILL, and the yield on 10 years U.S. government bonds, LONG. These asset return variables (in addition to the 1-year moving average of the 3-month

or,

$$
\ln \left(\frac{R_{t}}{Y_{t}}\right)=\Gamma+(\bar{\beta}+\beta)^{\prime} X_{t}+\epsilon_{t},
$$

where $\bar{\beta}$ captures the "automatic" response of the central bank to exogenous shocks. It follows that policy component in this modified model consists of $\Gamma+\bar{\beta} X_{t}$. However, because it is not possible to estimate the policy response to exogenous shocks I assume constant policy response to exogenous shocks; that is, the assumption I make is that $\bar{\beta}+\beta$ is constant. Although the assumption is very strong it is not unusual in policy modeling. This argument is similar to the inflation targeting model developed by Tylor (1993). Taylor rule is simple monetary policy rule that prescribe how a central bank should adjust its interest rate policy instrument in a systematic manner in response to developments in inflation and macroeconomic activity. The rule can be written as follows:

$$
i_{t}=i_{t}^{*}+a\left(\pi_{t}-\pi_{t}^{*}\right)+b\left(y_{t}-\bar{y}_{t}\right)
$$

In this equation, $i_{t}$ it is the target short-term nominal interest rate (e.g. the federal funds rate in the US), $\pi_{t}$ is the rate of inflation as measured by the GDP deflator, $\pi_{t}^{*}$ is the desired rate of inflation, $i_{t}^{*}$ is the assumed equilibrium real interest rate, $y_{t}$ is the logarithm of real GDP, and $\bar{y}_{t}$ is the logarithm of potential output. $\left(\pi_{t}-\pi_{t}^{*}\right)$ and $\left(y_{t}-\bar{y}_{t}\right)$ are partially functions of policy responses to exogenous shocks and the parameters $a$ and $b$ are considered constant. See Sørensen and Whitta-Jacobsen (2005) chapter 19, pp.559-560 and chapter 20, pp.611-612 for complete exposure and discussion. 
treasury bill rate TBMA), or linear combinations of them, have been found to forecast asset returns and are discussed in more detail in Campbell (1996). For my purposes, I view these variables as picking up key components of the shocks affecting the world economy. As for the oil variables, I consider (log of) crude oil price, LCOP, and (log of) U.S imports of crude oil from Mexico, LUSMCO. Since Mexico is a small open economy, it is reasonable to assume that shock variables are not influenced by Mexican monetary policy. I also define an additional explanatory variable, DUMMY, which takes the value of one after the Tequila crisis (1994:Q4) and zero otherwise.

\subsubsection{Contribution of Traditional Variables}

Since the data available for the traditional variables span over a shorter period than the data available for the dependent variables I consider the reduced sample period for this section (1985:Q4-2006:Q4). I test for time-series properties of each series by conducting augmented Dickey and Fuller (1979) (hereafter, ADF) and Phillips and Perron (1988) (hereafter, PP) tests. In both tests, I cannot reject the null hypothesis of a unit root for $L I M P$ and $L M 2$. As for OPPCOST and EXPV I get mixed results. For FO, EXRV, and foreign reserves, FR, both tests reject the null hypothesis of unit root. So, I take the first difference of the $L I M P$ and $L M 2$ then estimate (2) by OLS, when $X_{t}$ is identified by the traditional variables. As results in column 1 of table 1 show, all the traditional variables are correctly signed, with exception of $\Delta L M 2,{ }^{10}$ but only EXPV is statistically significant. As predicted by most studies in the literature, foreign reserves are positively correlated with exports volatility and imports. Financial openness is positively correlated with foreign reserves confirming the importance of capital flows in the accumulation of reserves. Note, however, that the traditional variables account for no more than $12 \%$ of the variation in reserves. This suggests that perhaps, as Figure A.1 (in the appendix) illustrates, the demand for reserves does not capture what we might a priori believe to be important determinants of reserves accumulation. Next, I run the same regression but include the dummy variable. Results are reported in Column 2. Although more coefficients are statistically significants, the model does not account for more than $31 \%$ of the variation in reserves.

The failure of the traditional variables in capturing the variation in demand for foreign reserves is not unexpected. For the decomposition method to work well, the observable vector $X_{t}$ should satisfy at least two conditions: (i) it contains variables that can capture a significant portion of exogenous shocks that affect the reserves accumulation, so that we can more confidently attribute changes in the intercept, $\Gamma_{t}$, to policy changes, and (ii) it only contains variables that are exogenous to monetary policy so that any policy changes will be captured in the policy component of model (2). The traditional variables considered here and widly discussed in the literature do not satisfy either of these conditions. As I pointed out, including a dummy improves the specification a little bit (i.e., coefficients more significance) but much of the variation is still unexplained. It is likely that shifts in imports and exports are sometimes induced by changes in trade policy, so that they cannot be thought as exogenous. Moreover, restrictions on capital outflows (e.g.,

\footnotetext{
${ }^{10}$ I expected $\triangle L M 2$, the potential for resident-based capital flight from the domestic currency, which is an indicator of capital account vulnerability, to be statistically significant and correctly signed. This is because of the increasing role for the self-insurance motive against potential internal drain. Rothenberg and Warnock (2006) find that almost half of the episodes of sudden stops are actually episodes of sudden flights.
} 
Table 1: Decomposing Foreign reserves

\begin{tabular}{|c|c|c|c|c|c|}
\hline & TDL & TDL \& D & Shocks & Shocks \& D & ECM \\
\hline$\overline{\Delta L I M P}$ & $\begin{array}{c}.15 \\
(0.26)\end{array}$ & $\begin{array}{c}.52 \\
(1.01)\end{array}$ & - & - & - \\
\hline$\Delta L M 2$ & $\begin{array}{c}-.20 \\
(-0.19)\end{array}$ & $\begin{array}{c}-.47 \\
(-0.50)\end{array}$ & - & - & - \\
\hline EXPV & $\begin{array}{c}3.01^{-05 * * *} \\
(3.68)\end{array}$ & $\begin{array}{l}2.2^{-06} \\
(0.24)\end{array}$ & - & - & - \\
\hline FO & $\begin{array}{c}1.73 \\
(0.77)\end{array}$ & $\begin{array}{l}1.29 \\
(0.65)\end{array}$ & - & - & - \\
\hline EXRV & $\begin{array}{c}.09 \\
(0.48)\end{array}$ & $\begin{array}{l}-.54^{* *} \\
(-2.52)\end{array}$ & - & - & - \\
\hline OPPCOST & $\begin{array}{c}.15 \\
(0.66)\end{array}$ & $\begin{array}{l}.57^{* *} \\
(2.57)\end{array}$ & - & - & - \\
\hline CONSTANT & $\begin{array}{c}-2.87^{* * *} \\
(-65.13)\end{array}$ & $\begin{array}{l}-3.26^{* * * *} \\
(-35.54)\end{array}$ & $\begin{array}{c}-2.91^{* * *} \\
(-26.93)\end{array}$ & $\begin{array}{l}-3.10^{* * *} \\
(-15.93)\end{array}$ & - \\
\hline DUMMY & - & $\begin{array}{l}.70^{* * *} \\
(4.77)\end{array}$ & - & $\begin{array}{c}.46 \\
(1.10)\end{array}$ & - \\
\hline LCOP & - & - & $\begin{array}{c}.38 \\
(.98)\end{array}$ & $\begin{array}{c}.54 \\
(1.49)\end{array}$ & .38 \\
\hline LUSMCO & - & - & $\begin{array}{c}-.89 \\
(-1.16)\end{array}$ & $\begin{array}{c}-1.77^{* *} \\
(-1.71)\end{array}$ & -.66 \\
\hline DIV & - & - & $\begin{array}{l}-4.43^{*} \\
(-1.39)\end{array}$ & $\begin{array}{c}-4.65^{* *} \\
(-1.72)\end{array}$ & -1.90 \\
\hline TBILL & - & - & $\begin{array}{l}-7.65 \\
(-1.03)\end{array}$ & $\begin{array}{r}-10.10^{*} \\
(-1.51)\end{array}$ & -2.75 \\
\hline LONG & - & - & $\begin{array}{l}-5.14 \\
(-.39)\end{array}$ & $\begin{array}{l}-5.50 \\
(-.49)\end{array}$ & -8.76 \\
\hline VWR & - & - & $\begin{array}{l}.43 \\
(.39)\end{array}$ & $\begin{array}{l}.35 \\
(.38)\end{array}$ & .26 \\
\hline $\begin{array}{l}\text { NOBS } \\
\bar{R}^{2}\end{array}$ & $\begin{array}{c}84 \\
.12 \\
{[0.0144]}\end{array}$ & $\begin{array}{c}84 \\
.31 \\
{[0.0000]}\end{array}$ & $\begin{array}{c}96 \\
.70 \\
{[0.000]}\end{array}$ & $\begin{array}{c}96 \\
.70 \\
{[0.000]}\end{array}$ & 103 \\
\hline
\end{tabular}

Notes: (1) t-statistics are given in parentheses. (2) P-values in square brackets.

${ }^{*}$ significance at $10 \%, 5 \%$ and $1 \%$ is referred to by ${ }^{*},{ }^{* *}$, and ${ }^{* * *}$, respectively.

capital controls) are induced by changes in the monetary policy and cannot be thought as exogenous.

\subsubsection{The Contribution of the Exogenous Shocks to Foreign Reserves}

Here I consider an alternative approach to adjusting foreign reserves movements for exogenous shocks. As outlined earlier, to identify shocks, I use two types of exogenous shocks (i) four indices of the market returns on a set of internationally traded financial assets, and (ii) two oil variables. If global asset markets were complete, then it would be possible to replicate the impact of all global economic shocks using some combination of market returns. This is sometimes referred to in the finance literature as the "spanning" property (see Duffie, 1986), and is analogous to the use of relative prices to infer sectoral productivity shocks under the assumption of competitive markets (e.g. investment-specific technical change). While, in 
reality, such markets are unlikely to be complete, I take this as a first approximation. The market return indices that I consider have been used extensively in the finance literature to represent underlying factors in stock market returns and to capture cyclical activity in the U.S. economy. As for the oil variables, it is not unreasonable to consider them as key variables driving foreign reserves in Mexico. Like many oil exporting countries, Mexico's business cycle is correlated with the price of oil, its main export good; so much so that this price has become a signal of aggregate conditions to (foreign and domestic) investors and policymakers alike in these countries. ${ }^{11}$ As a result of the many internal and external reactions to this signal, the change in Mexican government revenue (and then the reserves accumulation in this country) is correlated with the crude oil price and U.S imports of crude oil from Mexico. Note that since Mexico is a small open economy, it is reasonable to assume that these international variables are not influenced by Mexican monetary policy.

As in the previous exercise, I test for time-series properties of each series by conducting ADF and PP tests but now the sample period is from 1981:Q1 to 2006:Q4, instead. I cannot reject the null hypothesis of a unit root for the dependent variable FR, and the explanatory variables LCOP, LUSMCO, DIV and LONG. This result motivates the use of cointegration methods for my analysis. More specifically, I apply the system cointegration approach developed in Johansen (1988) to determine whether there is any evidence of a longrun relationship between the foreign reserves in Mexico and the the crude oil price, U.S. imports of crude oil from Mexico, dividend yields, and the yield on 10 years U.S. government bonds. Johansen's testing procedure strongly rejects the null hypothesis of no cointegartion and fails to reject the null hypothesis of at most 1 cointegration equation. ADF and PP tests for TBILL and VWR suggest that we reject the null hypothesis of a unit root. The time-series properties of all series suggest that we estimate elasticities via dynamic OLS. The estimation method proposed here is based on Saikkonen (1991), Phillips and Loretan (1991), Stock and Watson (1993), and Wooldridge (1991). This method consists at augmenting model (2) with leads and lags of I(1) explanatory variables (LCOP, LUSMCO, DIV, LONG) to correct for the autocorrelation in error terms. The estimation results are presented in column 3 of table 1.

The results illustrate the striking fact that $70 \%$ of the variation in foreign reserves can be replicated by a simple linear combination of the asset returns and oil variables. The simple correlations between the reserves and the asset return variables, except for the VWR are consistent with the theoretical predictions. In fact, DIV, TBILL, and LONG are negatively correlated with foreign reserves. The treasury bill rate is viewed as an indicator of short run opportunities in the U.S economy. An increase in TBILL results in capital outflows and then affects negatively the stock of foreign reserves. Dividends in the finance literature are used to forecast the future U.S. growth. An increase of DIV will result in capital outflows to the U.S and

\footnotetext{
${ }^{11}$ According to the 2006 annual report of the International Energy Agency, IEA, Mexico is the sixth-largest producer of oil in the world. Mexico produced an average of 3.7 million barrels per day in 2006 and 3.6 million barrels per day in 2007. Of Mexico's oil production, about 88 percent was crude oil and condensate, the rest consisting of natural gas liquids (NGL) and refinery gain. The oil sector is a crucial component of Mexico's economy. That is, the oil sector generates over 10 percent of the country's export earnings and one-third of government revenues. Again, according to the IEA, Mexico is the tenth largest oil net exporter of oil in the world. Moreover, according to the Oil and Gas Journal (OGJ), Mexico had 12.9 billion barrels of proven oil reserves as of January 1, 2006, the third-largest amount of conventional crude oil reserves in the Western Hemisphere. Most reserves consist of heavy crude oil varieties.
} 
consequently the stock of reserves is negatively affected. The RBC literature views the yields on 10-years U.S. government bonds as a good indicator of the U.S. RBC meaning that an increase in LONG reflects good expectation about the U.S RBC and then we should expect capital outflows and/or slowdown in capital inflows, a result confirmed by the sign of the coefficient on LONG. As for the correlations between the foreign reserves in Mexico and the oil variables they are correctly signed. An increase in the crude oil price generates more revenue to the Mexican government and increases the stock of foreign reserves. An increase in U.S imports of crude oil from Mexico indicates more favorable economic conditions in the U.S and capital flows to Mexico might be negatively affected which might result in negative effect on reserves. Figure 1 shows the actual and fitted foreign reserves implied by the relationship between foreign reserves in Mexico and the exogenous shocks.

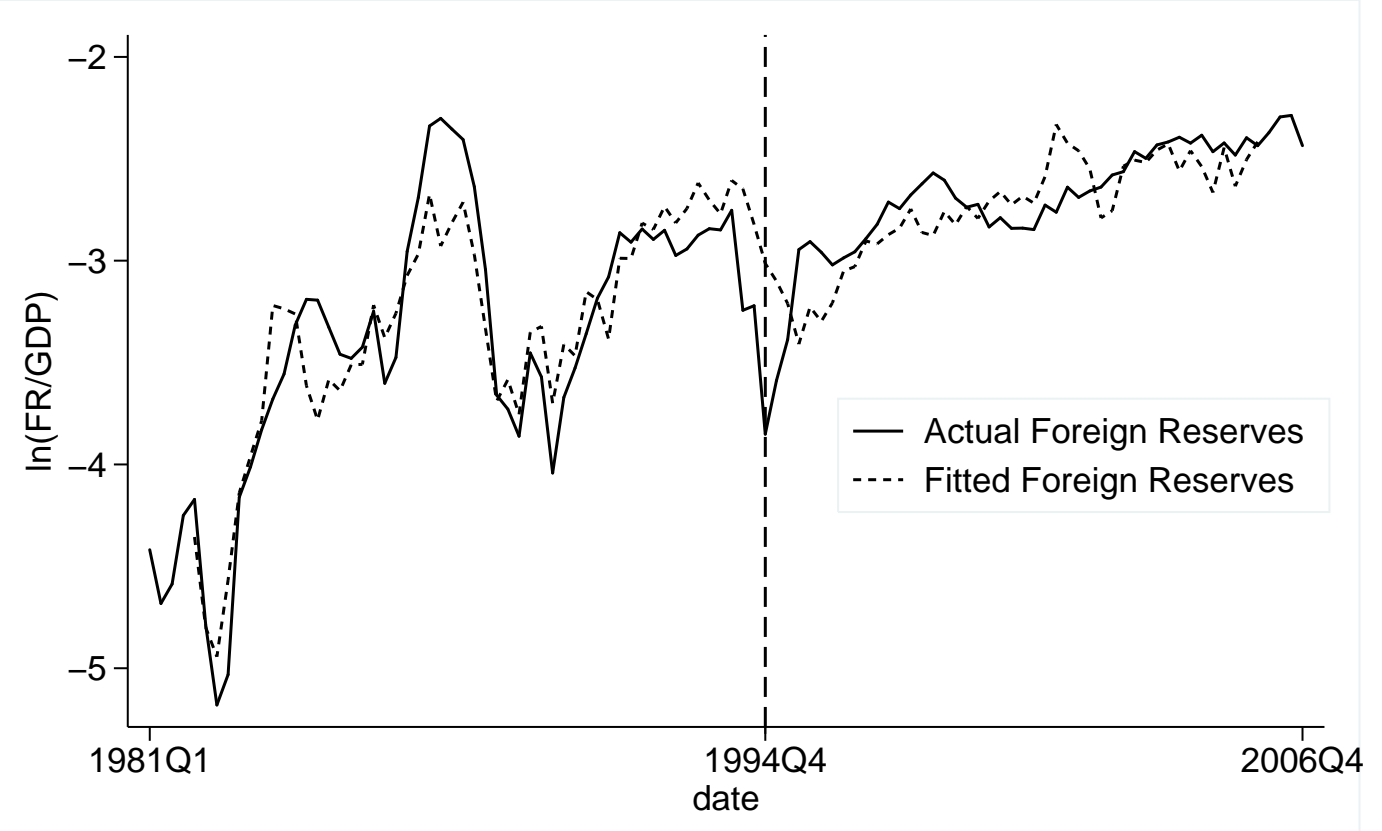

Figure 1: Contribution of Exogenous Shocks to Foreign Reserves Accumulation in Mexico

The above exercise suggests that external shocks represent a good approximation of the factors driving the reserves accumulation in Mexico. This is an interesting finding and supports our fundamental assumption that the significant increase in foreign reserves in Mexico is not necessarily the result of a policy adjustment only that took place in the aftermath of the Tequila Crisis. To explore this interpretation further, I ran the same regression but included a dummy variable which took on the value 1 after 1994 and zero otherwise. As the results in column 4 of Table 1 indicate the coefficient on this dummy is statistically insignificant however Chow test suggests that the long run reserves to GDP ratio did change slightly. As discussed in the decomposition method, the constant term in this regression captures the permanent 
component of the government's policy variable. The model suggests that over the period 1981-2006, the long run policy target (i.e., foreign reserves to GDP) is 5.5\%. By accounting for the structural break (i.e., introducing a dummy variable) the long run policy component increases to $7.1 \%$. That is, an increase of the reserves to GDP target by $1.6 \% .{ }^{12}$ Figure 2 depicts the fitted values from regressions of foreign reserves on a constant (dashed line) and constant and the dummy (the straight line with a jump), which might be viewed as an estimate of the non-shocks-adjusted foreign reserves. The non-shocks-adjusted foreign reserves suggests that there might be a policy shift in the aftermath of the Tequila crisis. However, by accounting for the shocks (Figure 1) the evidence of policy shift disappears. According to my interpretation, the increase in reserves target is explained by both policy adjustment and external shocks. While, the data for Mexico suggest that foreign reserves increased by 3.0\% between 1994:Q4 and 2006:Q4, the model implies that policy adjustment only does not account for the whole increase in foreign reserves. Column 5 of Table 1 reports the parameters of the cointegrating vector implied by an error-correction model. The estimates are close to those implied by the dynamic OLS regression (column 3), suggesting that my not misspecified.

Based on these empirical results, we interpret the Mexican's foreign reserves accumulation process as follows: Under the policy regimes that were in place up to the mid-1990s, exogenous global shocks accounted for $70 \%$ of the variation in the demand for international reserves. In the mid-1990s, however, exogenous shocks caused a period of liquidity problems and resulted in high demand of foreign reserves. The Mexican government did increase its long-run target of reserves to GDP slightly. This adjustment along with more favorable exogenous shocks in the post crisis period accounted for the increase in level of international reserves observed in the data.

\section{Adequacy of Foreign Reserves}

What level of foreign reserves should the central bank hold? The heyday of the reserve adequacy literature dates back to the 1960s and the 1970s, when the focus was mainly on the current account. The main framework of this literature has been the Baumol-Tobin inventory model with fixed costs of depleting and replenishing reserves (see Frenkel and Jovanovic, 1981, and Flood and Marion, 2002 for recent review). ${ }^{13}$ The main prediction of the model is a positive correlation between the volatility and the level of international reserves, and it has been found to hold very robustly in the data. However, the model has not been used normatively to estimate the optimal level of reserves.

\footnotetext{
${ }^{12}$ Recall that I estimate the model $\ln \left(\frac{R_{t}}{Y_{t}}\right)=\Gamma_{t}+\beta^{\prime} X_{t}+\epsilon_{t}$, so the long run reserves to GDP ratio, is$$
R_{t}^{*}=e^{\hat{\Gamma}_{t}}=5.5 \%
$$

when I include a dummy variable to account for the structural break the long-run ratio of reserves to GDP becomes

$$
\tilde{R}_{t}=e^{\hat{\Gamma}_{t}+\hat{\beta}_{d u m m y}}=7.1 \%
$$

${ }^{13}$ The basic non-stochastic model of the demand for money was developed by Baumol (1952) and Tobin (1956). 


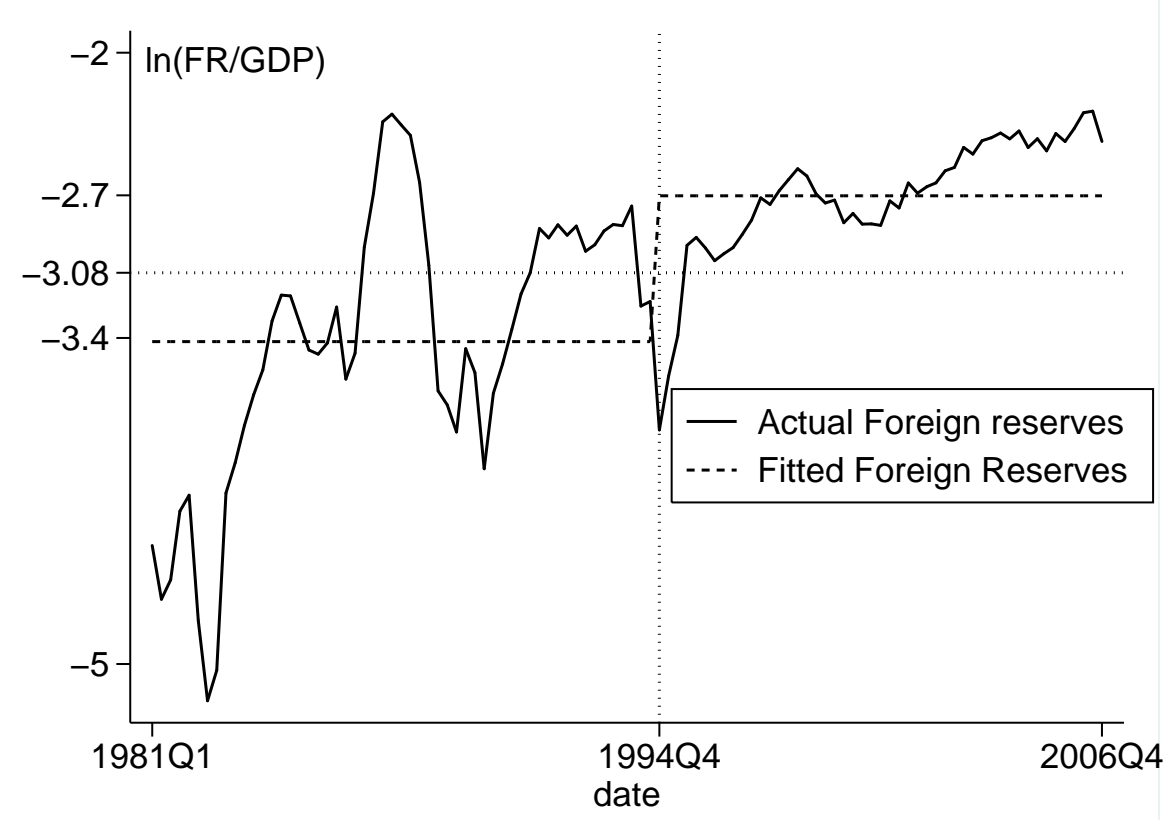

Figure 2: Constant vs. Constant and Dummy

In recent years, few papers attempted to characterize the optimal level of reserves for emerging market countries that face the risk of sudden stops. Alfaro and Kanczuk (2006) study the joint decision of holding sovereign debt and reserves. Their results suggest that the optimal policy is not to hold reserves at all. Jeanne (2007) develops a simple welfare-based model of the optimal level of reserves to deal with the risk of capital account crises or of "sudden stops" in capital flows. He finds that it is not difficult for the model to explain a reserves-GDP ratio on the order of 10 percent for the typical emerging market country (close to the long-run historical average), and that even higher ratios can be justified if one assumes that reserves have a significant role in crisis prevention. He concludes that levels of reserves observed in many countries in the recent period, in particular in Latin America, are within the range of the model's predictions.

Other studies have developed models that allow reserves to have the additional effect of helping to prevent the onset of a sudden stop. Bussière and Mulder (1999); Mody and Taylor (2002); Garcia and Soto (2004); Sachs, Tornell, and Velasco (1996); and Chamon, Manasse, and Prati (2007) argue and find support for the proposition that reserves may lower the likelihood of a crisis. Countries with large holdings of reserves may inspire confidence and be less susceptible to panic leading to self-fulfilling crises. ${ }^{14}$ This is consistent with the approach of the major credit rating agencies, which factor in reserve holdings when determining sovereign credit ratings.

In sum, it is quite non-controversial to state that, other things being equal, foreign reserves help absorb

\footnotetext{
${ }^{14}$ Even in first generation models, such as Krugman (1979), additional reserves affect the timing of a crisis.
} 
unexpected (external) shocks and smooth current and capital account imbalances. The question, of course, is how many reserves an economy need to hold? Although this question has been asked many times in the resent past, it has not received a satisfactory answer. This is why policymakers have been using old rules of thumb which I outlined in the introduction (see Bird and Rajan, 2003, for a more detailed discussion). In fact, the official statements usually point to the need of building up international reserves to fend off external shocks and speculative attacks but do not offer a target level based on fundamental considerations. For instance, an official in Korea's central bank said "(T)here is no such thing as too much foreign international reserves." On China's international reserve holding, a Chinese official argued that there is "no unified benchmark on the appropriate amount of forex international reserve a country should hold in both theory and practice" and "it could not be said to be 'excessive' or 'deficient' ". ${ }^{15}$

It might be that the lack of applicability of theoretical predictions of optimal reserves holdings led to their non implementations. Policymakers usual need tools and mechanisms that are simple and easy to use, but most importantly that satisfy their political concerns. Clearly, policymakers want to avoid external (and domestic) crises. But with increasing financial and trade openness (and with it the increasing risk) it is less likely that an economy can be fully insured against external imbalances. Nonetheless, policymakers can adopt strategies to reduce the likelihood of the crisis. In our context, I introduce a flexible and practical approach to assess the policy of holding reserves as insurance tool.

\subsection{The Notions of Sustainability, and Adequacy}

Here, I introduce a concept of BOP sustainability that can accommodate a variety of future behaviour patterns and allows the stock of reserves to influence the likelihood of BOP crises. Traditionally this has been done by investigating the external insolvency condition. Solvency is defined theoretically in relation to an economy's present value budget constraint. By this definition, an economy is solvent if the present discounted value of future trade surpluses is equal to current external indebtedness. ${ }^{16}$ The practical applicability of this definition, however, is inhibited by the fact that it relies on future events and policy decisions, without imposing any structure on them. Few studies have therefore attempted to define a baseline for future policy actions (See for example Corsetti and Roubini, 1991). This gives rise to the notion of sustainability-the current policy stance is sustainable if its continuation into the indefinite future does not violate solvency (budget) constraints (Milesi-Ferretti and Razin, 1996).

Defining sustainability in relation to solvency is complex for current-account imbalances, because current-account imbalances reflect the interaction among the savings and investment decisions of the government and the domestic private agents, as well as the lending decisions of foreign investors. Although government decisions may at first be taken as given, private-sector decisions may not. An alternative way of asking whether a continuation of the current policy stance is going to require a "drastic" policy shift or lead to a "crisis". If the answer is yes, the imbalance is unsustainable. Such a drastic change in policy or crisis situation may be triggered by a shock, either domestic or external, which causes a shift in the

\footnotetext{
${ }^{15}$ Day and Choi (2004) and Xinhua News Agency (2004).

${ }^{16}$ See Glick and Rogoff(1995), Razin (1993) and Liederman and Razin (1991).
} 
confidence of domestic and foreign investors and a reversal of international capital flows. The framework I develop here addresses this question, and investigates whether a policy change (i.e., drastic policy shift) has taken place when the Tequila crisis hit the Mexican economy. I also produce a prediction of crisis, under the current policy stance.

In particular, I introduce a sustainability condition that accounts for all liabilities in the economy (not only external debt such as government and private agents external borrowing), and allows the reserves holdings to influence the likelihood of BOP crises. In addition, my definition of sustainability takes into account the fact that not all the assets an economy holds are liquid. In fact, the economy might not be able to liquidate its assets in a short time to satisfy its international obligations. And, even if the assets are highly liquid the country might not be willing to liquidate them and ends up with no assets. The debt and financial crises of the 1980s and 1990s showed that countries choose to default on their external debt while they still hold assets. The sustainability condition I define in this paper accounts for this possibility. This way, I implicitly relate the sustainability of an economy to the perception of foreign investors about the country's inability or unwillingness to meet its external obligations. This approach provides a basis for a flexible and simple method for determining the implicit market assessment of a country's external position and serves as an effective and practical tool to evaluate the adequacy of reserves policy (i.e target ratio of reserves to GDP).

Using the assumption that reserves are ultimately being accumulated to service liabilities and to affect the perception of foreign investors, I address the adequacy of reserves holdings, based on sustainability. If the (long-run) reserves target is able to prevent unsustainability then it is adequate. The sustainability condition I discuss here is

$$
R_{t}+\widetilde{P V}_{t}\left(T B_{t}\right)-N L_{t} \geq \phi Y_{t} .
$$

where, $R_{t}$ is the stock of reserves, $\widetilde{P V}_{t}\left(T B_{t}\right)$ is the present discounted value of the trade balance, under a given policy stance, $N L_{t}$ is the net liability (all liabilities minus all non-reserves assets) position of the economy at time $t$, and $Y_{t}$ is the GDP. The parameter $\phi$ captures foreign investors perception about the country's inability or unwillingness to meet its external obligations. We can think of $\phi$ as the critical value of the net asset position that triggers a crisis. If this sustainability condition is satisfied then the reserves target is adequate. But if it is violated, then there is a need to change the policy (unless bailed out). Therefore, the natural question in evaluating reserves policy in emerging economies is whether the current targets are adequate and whether they are effective in preventing crisis (i.e., unsustainability), and how big $\phi$ should be for the economy to gain credibility from the outside partners. To answer these questions I need first to calculate the trade balance, then calculate its discounted present value, under the current policy stance. The remaining of this section uses the BOP equation to derive the trade balance, then uses the decomposition method discussed in the previous section to estimate the trade balance movements. 


\subsection{Trade Balance}

In an open economy, the BOP equation is

$$
C A_{t}+K A_{t}=\Delta R_{t}
$$

where $K A_{t}$ is the financial account, ${ }^{17} C A_{t}$ is the current account, and $\Delta R_{t}=R_{t}-R_{t-1}$, is the change in reserves. The capital account, in turn, can be written as,

$$
C A_{t}=T B_{t}+I T_{t}
$$

where $I T_{t}$ is the net income transfers. Combining (4) and (5) we get

$$
T B_{t}+I T_{t}+K A_{t}=\Delta R_{t}
$$

The financial account, $K A_{t}$, represents the change in the net liabilities position of the country. ${ }^{18}$ That is,

$$
K A_{t}=N L_{t}-N L_{t-1}
$$

where,

$$
N L_{t}=\text { All Liabilities - All Assets. }
$$

Combining equations (4)-(7) we can write trade balance as follow

$$
T B_{t}=\Delta R_{t}-\Delta N L_{t}-I T_{t}
$$

which represents the net income of the whole economy.

Next, I adopt the same decomposition used in the section 2 to approximate the processes driving net liabilities $N L_{t}$, and income transfers, $I T_{t}$. That is,

$$
\ln \left(\frac{N L_{t}}{Y_{t}}\right)=N L+\alpha^{\prime} X_{t}+\mu_{t}
$$

and

$$
\ln \left(\frac{I T_{t}}{Y_{t}}\right)=I \bar{T}+\gamma^{\prime} X_{t}+\xi_{t}
$$

where $\mu_{t}$ and $\xi_{t}$ are the residuals for net liabilities and income transfers, respectively, that are not captured by the observables. Because our focus is on reserves policy target, I assume that $\bar{N} L$ and $I \bar{T}$ could be

\footnotetext{
${ }^{17}$ The financial account was formally called the capital account. I will use the two terms interchangeably

18" The financial account records, by type of financial instrument, the changes in the financial assets and liabilities" (OECD (2001): Glossary of Statistical Terms. Source of Publication ESA 8.50-8.51 [III.2]. http://stats.oecd.org/glossary/detail.asp?ID=960).

"The financial account covers all transactions, including the creation and liquidation of financial claims, associated with change of ownership in international financial assets and liabilities" (Balance of Payments Sources and Methods, Central bank of New Zealand, 2004).
} 
Table 2: Decomposing Net Liabilities and Income Transfers: Dynamic OLS

\begin{tabular}{|l|c|c|c|c|}
\hline & Net Liab. & NL \& Dummy & I.Transfers & IT \& Dummy \\
\hline LCOP & $-.46^{* *}$ & -.25 & $-.65^{* * *}$ & $-.46^{* * *}$ \\
& $(-2.13)$ & $(1.01)$ & $(-2.79)$ & $(-2.89)$ \\
LUSMCO & $1.76^{* * *}$ & .56 & .61 & $-.83^{*}$ \\
DIV & $(4.13)$ & $(.80)$ & $(1.31)$ & $(-1.83)$ \\
& .17 & -.13 & 1.17 & 1.15 \\
TBILL & $(.10)$ & $(-.07)$ & $(.61)$ & $(0.94)$ \\
& -5.03 & $-8.39^{* *}$ & .54 & -4.37 \\
LONG & $(-1.23)$ & $(-1.84)$ & $(.12)$ & $(-1.42)$ \\
& 3.18 & 2.69 & $19.69^{* * *}$ & $19.18^{* * *}$ \\
VWR & $(.44)$ & $(.36)$ & $(2.52)$ & $(3.82)$ \\
& -.22 & -.33 & .25 & .08 \\
DUMMY & $(-.38)$ & $(-.53)$ & $(.39)$ & $(0.20)$ \\
& - & $.63^{* *}$ & - & $.80^{* * *}$ \\
CONSTANT & $-1.51^{* * *}$ & $(2.21)$ & & $(4.22)$ \\
& $(-25.38)$ & $\left(-1.77^{* * *}\right.$ & $-4.82^{* * *}$ & $-5.14^{* * *}$ \\
NOBS & 96 & 96 & $(-74.27)$ & $(-58.30)$ \\
$\bar{R}^{2}$ & .92 & .95 & 96 & 96 \\
& {$[0.000]$} & {$[0.000]$} & {$[0.000]$} & {$[0.000]$} \\
\hline
\end{tabular}

interpreted as policy targets or means and I will take them as given when assessing the reserves policy. I use the same vector of observable variables (LCOP, LUSMCO, DIV, TBILL, LONG, AND VWR) to identify shocks to the trade balance components, $N L_{t}$ and $I T_{t}$. Time series properties for $N L_{t}$ and $I T_{t}$ over the sample period 1981:Q1 to 2006:Q4 are tested using ADF and PP tests. For all instances I cannot reject the null hypothesis of a unit root. Next I test for cointegration of each series with the shock variables. The testing procedure strongly rejects the null hypothesis of no cointegration. This motivates the estimation of (9) and (10) by dynamic OLS. Table 2 summarizes the results. My findings suggest that external shocks replicate well movements in net liabilities and income transfers. In fact, as can be seen in Columns 1 and 3, external shocks explain $92 \%$ of the variation in net liabilities and $72 \%$ of income transfers, respectively. As Figures 3 and 4 show, the model replicates the movements in both processes.

\section{Assessing Foreign Reserves Policy}

The notion of adequacy I proposed in the previous section suggests that the ratio reserves-GDP an economy can afford depends on future trade surplus (i.e, trade balance), which are functions of foreign reserves, net liabilities, and income transfers, which are in turn functions of the exogenous shocks, as well as the policies in place. According to our sustainability condition defined by (3), for a given financial policy, whether a certain level of reserves-GDP ratio is viewed adequate depends crucially on what the expected future 


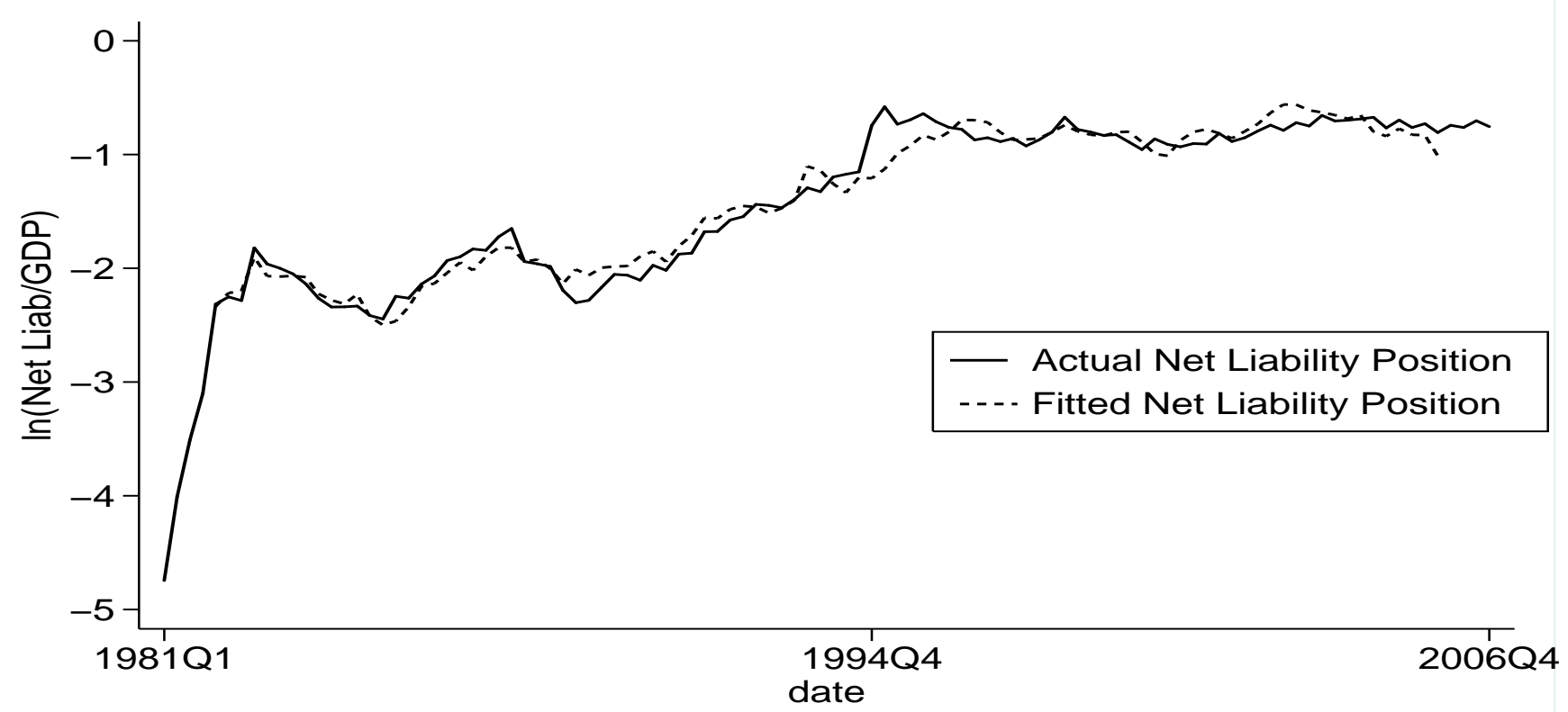

Figure 3: Contribution of Exogenous Shocks to Net Liabilities Process

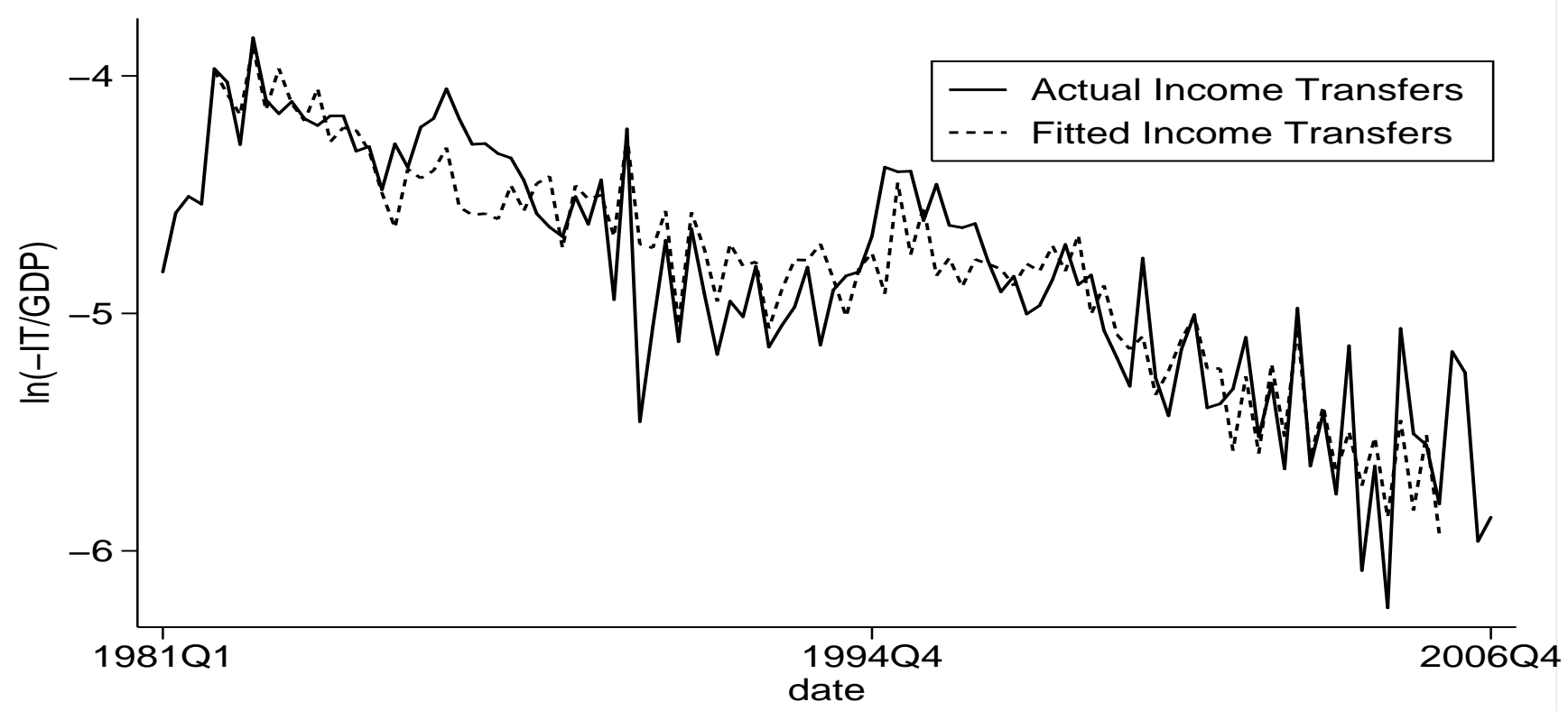

Figure 4: Contribution of Exogenous Shocks to Income Transfers Process 
trade surpluses are. As the state of an economy evolves, expectation of future trade surpluses may change too. Therefore, it is not meaningful to ask what level of the reserves-GNP ratio can the economy afford independent of the state of the global (and domestic economy).

\subsection{Assumptions for Valuation of Trade Balance}

I assume that there is a complete world financial market in which all contingent claims with payoffs that are functions of the set of the exogenous shocks, $Z_{t}$, can be traded. Under this assumption and the assumption of no-arbitrage, there exists a unique sequence of stochastic discount factors, $\left\{M_{t}\right\}_{t \succeq 0}$, such that the time $t$ price of a contingent claim pays $q\left(Z_{t}\right)$ units of the consumption good in period $t+j$ is

$$
P(t, j)=E_{t}\left[\frac{M_{t+j}}{M_{t}} q\left(Z_{t+j}\right)\right]
$$

Since I assume that Mexico is a small open economy, so the stochastic discount factors are exogenous with respect to domestic agents' actions.

Given our specification for the trade balance in (8) and the processes driving it given by (2), (9) and (10), if the central bank's reserves policy continues to be $R_{t}^{*}$ (captured by $\Gamma_{t}$ ) in the future, the country's wealth can be expressed as

$$
\widetilde{P V}_{t}(\Lambda, Z)=\frac{1}{M_{t}} E_{t}\left[\sum_{j=1}^{\infty} M_{t+j}\left([\underbrace{R_{t+j}-R_{t+j-1}}_{\Delta R_{t+j}}]-[\underbrace{N L_{t+j}-N L_{t+j-1}}_{\Delta N L_{t+j}}]-I T_{t+j}\right)\right]
$$

where $\Lambda=\{\Gamma, \bar{N} L, I T\}$ and $\widetilde{P V}_{t}($.$) is the present discounted value under a given policy stance.$

To compute the market valuation, $\widetilde{P V}_{t}(\Lambda, Z)$, we need to specify a process for the the stochastic discount factor, $M_{t}$, applied by the market in valuing future cash-flows. Moreover, since movements in the discount factor will also reflect global shocks, an important determinant of the present value is its covariance with the trade surpluses. I take "the market" to be a representative U.S investor and assume that the "state of the world" is captured by the asset return indices and the oil variables discussed in the previous section. Specifically, I assume that the vector

$$
X_{t}=\left(X_{1, t}, X_{2, t}, X_{3, t}, X_{4, t}, X_{5, t}, X_{6, t}\right)=\left(L C O P_{t}, L U S M C O_{t}, D I V_{t}, T B I L L_{t}, L O N G_{t}, V W R_{t}\right)
$$

follows a vector autoregressive process:

$$
X_{t}=A X_{t-1}+\mathbf{u}_{t}
$$

where $\mathbf{A}$ is $6 \times 6$ matrix of parameters, and $\mathbf{u}_{t}$ is a $6 \times 1$ vector, $\mathbf{u}_{t}$ is i.i.d., and $\mathbf{u}_{t} \sim N(0, \Sigma)$. Table 3 provides the estimated process using quarterly data from 1981:Q1 to 2006:Q4.

\subsection{Asset Pricing Model}

To calibrate the model for the stochastic discount factor I use the approach of Lloyd-Ellis and Zhu (2001, 2006). Let $r_{t}^{T B I L L}$ be the interest rate on the 3-month Treasury bills, $r_{t}^{L O N G}$ to be the yield on 10 -year 
Treasury bonds, and $R^{m}$ to be the nominal return on the market portfolio. Then, the following no-arbitrage conditions should hold for any asset pricing model:

$$
\begin{gathered}
E_{t}\left[\frac{M_{t+1}}{M_{t}} \exp \left(r_{t}^{T B I L L}\right)\right]=1, \\
E_{t}\left[\frac{\frac{1}{2}\left(\sum_{j=1}^{20} M_{t+2 j} r_{t}^{L O N G}\right)+M_{t+40}}{M_{t}}\right]=1, \\
E_{t}\left[\frac{M_{t+1}}{M_{t}} R_{t+1}^{m}\right]=1 .
\end{gathered}
$$

where $r_{t}^{T B I L L}=E\left[r_{t}^{T B I L L}\right]+\frac{1}{4} X_{4, t}, r_{t}^{L O N G}=E\left[r_{t}^{L O N G}\right]+X_{5, t}$, and $R^{m}=\exp \left(X_{6, t}\right)$.

Since I use the stochastic discount factors to value cash-flows that are functions of $X_{t}$; it is important to model the covariance between the stochastic discount factors and $X_{t}$. Here, I adopt the following linear specification for the growth rate of the nominal stochastic discount factor:

$$
-\ln \left(\frac{M_{t}}{M_{t-1}}\right)=\varpi+\mathbf{b}^{\prime} X_{t-1}+\omega_{t}
$$

where $\omega_{t}$ is i.i.d., $\omega_{t} \sim N\left(0, \sigma_{\omega}^{2}\right)$, and $E\left[\omega_{t} \mathbf{u}_{t}\right]=\mathbf{v}$.

In my calculations, I focus on the special case of this specification which has been adopted by Lloyd-Ellis and Zhu (2006). ${ }^{19}$ Specifically I adopt the following specification for the growth in the discount factor:

$$
-\ln \left(\frac{M_{t}}{M_{t-1}}\right)=r_{t-1}^{T B I L L}+\frac{1}{2} \sigma_{\omega}^{2}+\omega_{t}
$$

By definition, $X_{4, t-1}=4\left(r_{t-1}^{T B I L L}-E\left[r_{t}^{T B I L L}\right]\right)$. So, the above equation is a special case of (17) with $\varpi=E\left[r_{t-1}^{T B I L L}\right]+\frac{1}{2} \sigma_{\omega}^{2}$, and $\mathbf{b}^{\prime}=(0,0,0,1 / 4,0,0)$.

We further assume that

$$
\omega_{t}=\rho_{4} \mathbf{u}_{4, t}+\rho_{6} \mathbf{u}_{6, t}
$$

That is, the the innovation in the stochastic discount factor is a linear combination of the innovation in the 3 -month interest rate and the innovation in the return on market portfolio. Then, we have

$$
\begin{gathered}
\sigma_{\omega}^{2}=\rho_{4}^{2} \sigma_{4, u}^{2}+\rho_{6}^{2} \sigma_{6, u}^{2}+2 \rho_{4} \rho_{6} \sigma_{46, u} \\
\mathbf{v}^{\prime}=\left(0,0,0, \rho_{4}, 0, \rho_{6}\right)^{\prime} \Sigma
\end{gathered}
$$

\footnotetext{
${ }^{19}$ Lloyd-Ellis and Zhu (2006) extend the term structure model discussed in Campbell and Viceira (1998) and Campbell, Lo and MacKinlay (1997) by allowing the innovation in the stochastic discount factor to be correlated with the innovations in the shock variables.
} 
The parameters $\rho_{4}$ and $\rho_{6}$ are calibrated so that the two moment conditions (15) and (16) hold. ${ }^{20}$ For more details on calibration and present value calculation, see Appendix.

\subsection{Historical Assessment of Sustainability}

Figure 5 illustrates the historical evolution of my estimate of Mexico's (net) future income (the present value of trade surpluses as a percentage of GDP plus the reserves-GDP ratio), under the current policy stance, in comparison with the liabilities-GDP ratio. As can be seen, while the liabilities-GDP ratio increase throughout the period, the future income floats around a constant but at a higher level than the liabilities-GDP ratio. Note, however, that in the mid-1990s Mexico experienced a large increase in its liability position and at the same time its net income experienced a significant drop getting very close to the lower bound of the sustainability condition described by (3). This refers to the financial distress that Mexico went through during the last quarter of 1994.

It is my view that the Mexican economy reached un upper bound on its accumulated liabilities by the end of 1994, which is when my earlier estimates suggest significant increase in net liability position (column 5 of Table 2). This is the point at which the net liability position reached a level that was considered unsustainable by outside investors, given the current state of the world and the current reserves policy. As a consequence, the net incomes (discounted present value plus foreign reserves) dropped significantly. The perception of foreign investors about the Mexico's inability and unwillingness to fulfil its external obligations reaches a high level in 1994. A calibrated version of sustainability condition defined by 8 indicates that the critical value of the net asset position that triggered the Tequila crisis is a bout $10 \%$ of GDP. That is $\phi=10 \%$.

This approach of assessing the adequacy of the reserves policy is much more useful than conventional rules of thumb, such as the Greenspan-Guidotti rule of full coverage of short-term debt, the ratio of 3 or 4 months of imports (e.g., Fisher, 2001), and the 5 to 20 percent rule of ratio of reserves to broad money (e.g., Calvo, 1996). The rules of thumb suggest, implicitly, that the central bank should adjust its reserve holdings whenever the lower bound (3 months of imports, short-term debt to GDP ratio of 1 , and a ratio of M2 to reserves of 5\%) is reached. In doing so, these rules do not account for the costs that the economy is subject to when adjusting its stock of reserves. The cost of adjustment, which is assumed to depend on the frequency of adjustment and on other costs, stems from the need to reduce expenditures relative to income so as to yield the desired BOP surplus that is necessary for the accumulation of reserves. ${ }^{21}$ These

\footnotetext{
${ }^{20}$ The sample period considered for calibration is slightly different from the sample I consider for estimation; that is, the model is calibrated for the period 1975:1-2003:4. Moreover, the asset pricing models considered here are homoscedastic, which implies that both the term premium and the equity premium are constant over time. In the data, however, these premiums are timevarying. Therefore, the calibrated parameters will be dependent on the sample period. I use parameters of Lloyd-Ellis and Zhu (2006). In their model they calculate the asset pricing model over the period 1975:1-2003:4. Since their model is covering all the period I am considering (except 2004:1-2006:4), I use their values.

${ }^{21}$ See Frenkel and Jovanovic (1981) for a discusiion of the adjustment costs an economy might incur.
} 


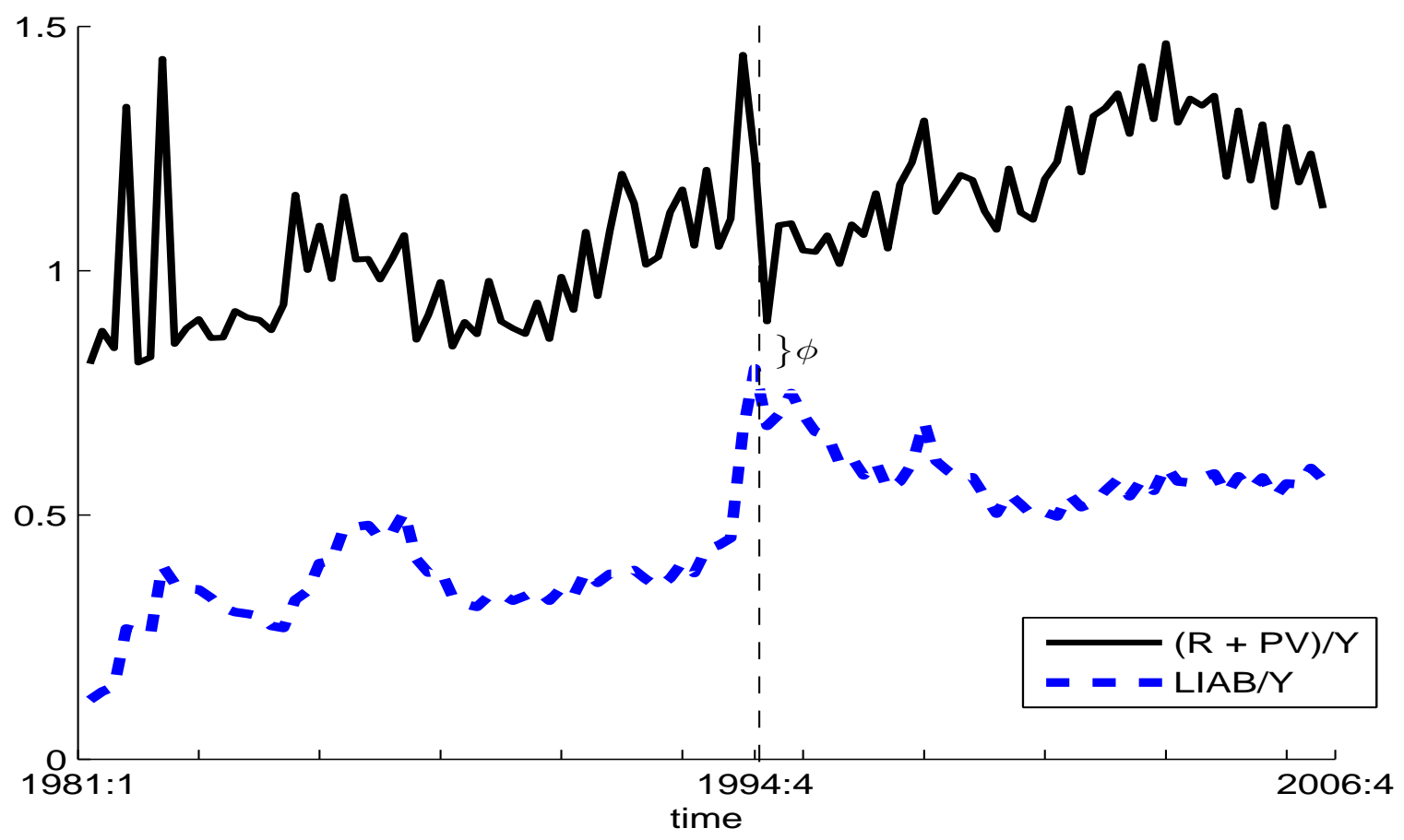

Figure 5: Historical Assessment of Reserves Policy in Mexico.

costs might be high enough to lead to even more unfavorable economic conditions. Moreover, these rules ignore the dynamics of the BOP, and do not provide a comprehensive framework for the reserves policy evaluations. The adequacy rule I develop in this paper fills the gap.

\subsection{Reserves Policy and Prediction of BOP Crises}

Since historically Mexico has violated its sustainability condition, it is important to investigate whether that unsustainability will occur in the future and whether that situation will be frequent, given the current policy and the risk coming from global conditions. To this end, I simulate the likelihood of violation of the sustainability condition defined by (8), under the current policy and given the shocks process defined by (13). Figure 6 illustrates the evolution over time of the simulated probability of violation of the sustainability condition (8). It is interesting to note that because the Mexican policy stance is sustainable in the recent years (the gap between future incomes and the net liability position is quite big since the mid-1990s, see Figure 5), the probability of unsustainability is zero over the first twelve periods (i.e., three years). However, given the increasing exposure to external shocks (more integration with the global financial and real markets) Mexico becomes more vulnerable to external imbalances. In fact, as can bee seen in Figure 5), the likelihood of unsustainability becomes positive after a the period of three years and continues to increase subsequently. This suggests that, although the current policy stance is effective in preventing BOP crises in the short run implying an adequate reserves policy, it is recommended that the 
policymaker in Mexico review future policies. However, whether the policymaker will change her reserves policy (i.e., reserves-GDP ratio) depends on her preferences, whether or not she is planning to stay in power, the expected cost of crisis, and the pressure she gets from outside agencies (e.g., IMF).

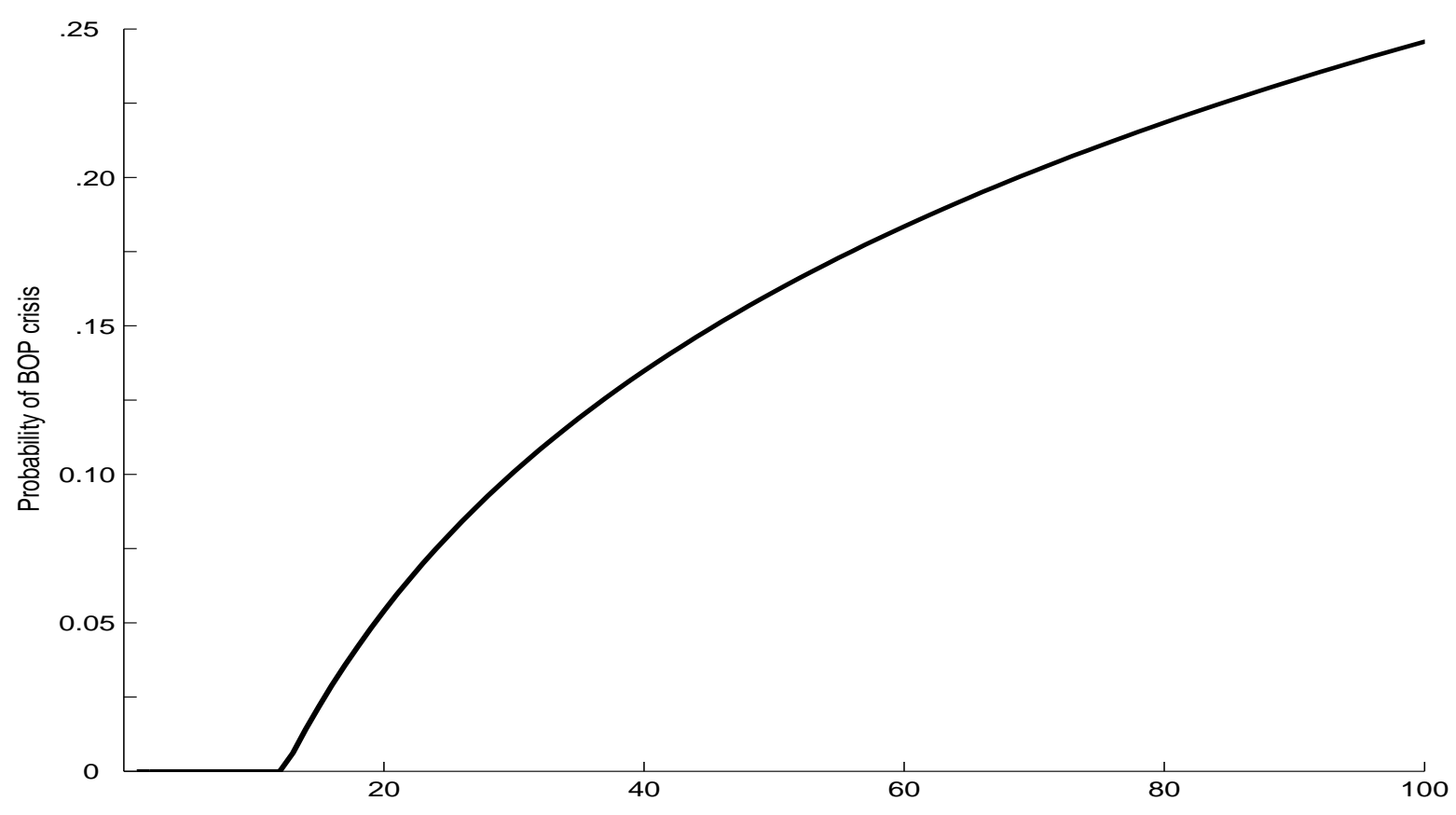

Figure 6: Probability of Unsustainability.

Blanco and Garber (1986) predict the timing and magnitude of devaluations forced by speculative attacks on fixed exchange rate systems. Using the Mexican experience as an example, they produce time-series estimates of the one-period-ahead probability of devaluation, the expected value of the new fixed exchange rate, and the confidence interval of the forecasted exchange rate. Their results show that devaluations, both in and out of sample, did occur when predicted by the model. Furthermore, the probabilities of devaluation reached relatively high values prior to actual devaluations. In their model, the central bank having fixed the exchange rate at some level, stops intervening in the foreign exchange market when net reserves reach a critical level. If such an event materializes at period $t$ the central bank establishes a new fixed exchange rate using a time-invariant policy rule. Under fixed exchange rate regime it is possible to identify and estimate the probabilities of devaluation along with the expected exchange rates, conditional on a devaluation in the next period. Under floating exchange rate regime, however, devaluation is not an option and the economy might end up in financial distress (i.e., BOP crisis). The only policy available to policymaker in my model is reserves. This leads to the question of what reserves target would control for the probability of BOP crisis.

To address this question, I assume that the policymaker doubles her (long run) reserves-GDP target, then simulate the evolution of the likelihood of BOP crisis. As Figure 7 shows, by doubling reserves-GDP target the probability of unsustainability is now zero for fifteen periods (it was 12 periods). Moreover, the 


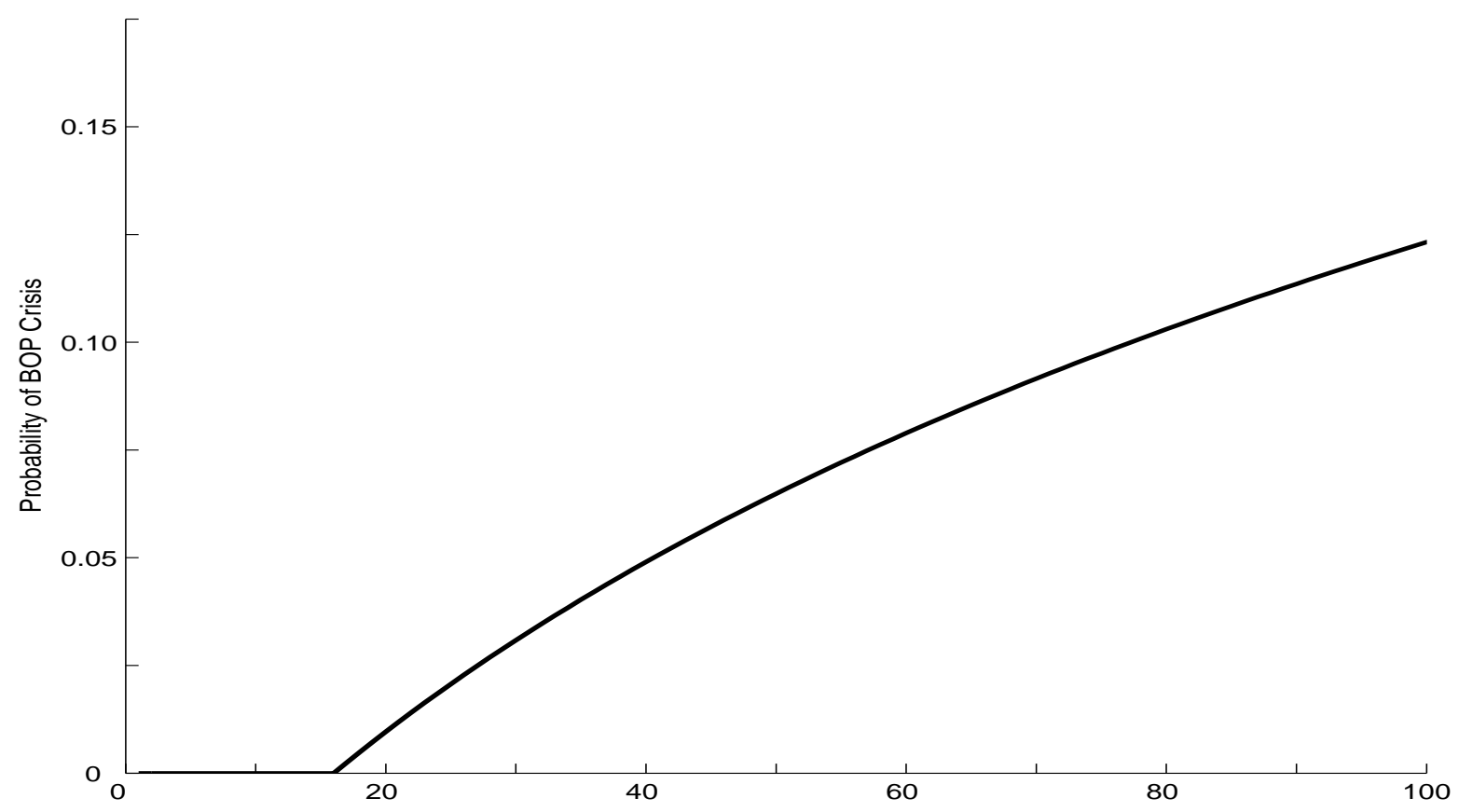

Figure 7: Probability of Unsustainability if Long Run Reserves-GDP Target Doubled.

probability increases at lower level. However, more reserves do not eliminate the risk of unsustainability completely.

\subsection{Adequacy Rule}

This approach to assessing the adequacy of reserves holdings is much more useful than the rules of thumb discussed in the earlier. It is a flexible tool that can accommodate many aspects of the economy. In fact, the assessment of adequacy here accounts explicitly for the shocks affecting the world economy, their size, their probability, and the cost (BOP crisis) associated with them. This method suggests that, given the domestic and global conditions, the stock of reserves the policymaker chooses to hold depends on her preferences, which is described by the maximum probability to tolerate, whether or not she is planning to stay in power, described by the time horizon she fixes in controlling for the probability of crisis, and the expected cost of a given policy stance (violation of the sustainability condition which leads to a BOP crisis). Figure 8 summarizes this approach. If the policymaker adopts a reserves target that satisfies both the time horizon and the maximum probability that can be tolerated, then it is adequate.

The advantage of this empirical method of assessing adequacy of foreign reserves holding is its applicability. It is a practical tool that policymakers can consider. The rules of thumb outlined above do not based on modeling approaches and then do not offer economic intuitions on why reserves should be at a paricular level. The existent literature on optimal reserves holdings a still in its early development and do not offer a common framework that central banks can adopt in considering what level of reserves to accumulate. 


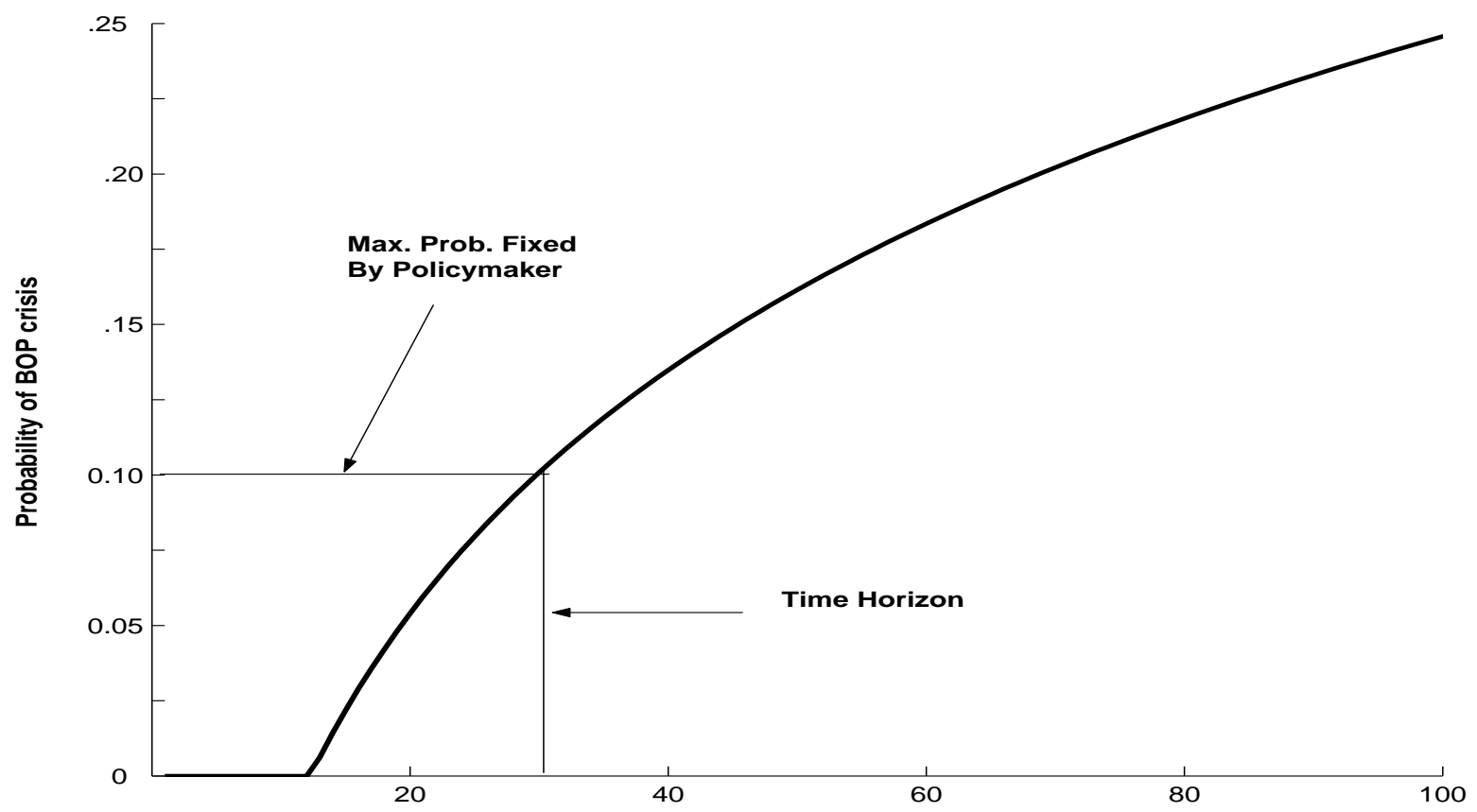

Figure 8: Adequacy Rule.

\section{Conclusion}

Increasing financial and trade openness exposes emerging market economies to unavoidable shocks that are outside the control of the local authorities. As a result many countries experienced liquidity problems and financial distress during the 1990s. The international finance literature has provide evidence that these countries opted for new policy: increase the international reserve holdings as a precautionary saving against future financial troubles. In this paper I have argued that external shocks (i.e., more favorable global conditions) are key determinants of the significant increase of foreign reserves accumulated by Mexico since the mid 1990s. Policy adjustment only cannot explain the observed increase. I argue that many of the shocks to the Mexican reserves can be replicated using a linear combination of internationally traded asset returns and oil variables. In fact, it is possible to approximate the reserves accumulation process over the last three decades as a stationary function of these shocks with some evidence of reserves policy adjustment after the Tequila crisis. My results are consistent with the hypothesis that the rise in reserves holdings experienced by Mexico was the result of a series of positive shocks in the post crisis period.

The strong and stable correlation between the foreign reserves and the external shocks provides a basis for a flexible and simple method for evaluating current reserves policy (i.e., target ratio reserves-GDP). A reserve target is adequate if the probability of unsustainability of the economy over a give time horizon is sufficiently low. Results suggest that, aside from 1994, historically, Mexico has satisfied its sustainability condition. However, although the reserves policy in place is effective in the short run, a BOP crisis is more likely in the long run. 


\section{References}

Aizenman, J. (2007): Large Hoarding of International Reserves and the Emerging Global Economic Architecture. National Bureau of Economic Research. Working Paper 13277.

Aizenman, J. and J. Lee. (2005): International Reserves: Precautionary Versus Mercantilist Views: Theory and Evidence. NBER Working Paper No. 11366.

Aizenman, J., Y. Lee, and Y. Rhee. (2004): International Reserves Management and Capital Mobility: Policy Considerations and a Case Study of Korea. NBER Working Paper No. 10534.

Aizenman, J. and Marion, N. (2003): The High Demand for International Reserves in the Far East: What's Going On? Journal of the Japanese and International Economies 17(3): 370-400.

Aizenman, J. and Marion, N. (2004): International Reserve Holdings with Sovereign risk and Costly Tax Collection. The Economic Journal 114, 569-591.

Alfaro, L., and Kanczuk, F. (2006): Optimal Reserve Management and Sovereign Debt. (unpublished; Cambridge, Massachussets: Harvard Business School).

Bank for International Settlements, BIS (2000): Managing Foreign Debt and Liquidity Risks. Policy Paper No. 8, BIS Monetary and Economic Department, Basel.

Baumol, W. J. (1952): The Transactions Demand for Cash: an Inventory Theoretic Approach. Quarterly Journal of Economics, Vol. 66 No. 4 (November), pp. 545-56.

Bird, G. and Rajan, R. S. (2003): Too good to be true?: the adequacy of international reserve holdings in an era of capital account crises. The World Economy, 26. pp. 873-891.

Bussière, M., and Mulder, C. (1999): External Vulnerability in Emerging Market Economies: How High Liquidity Can Offset Weak Fundamentals and the Effects of Contagion. IMF Working Paper 99/88.

Calvo, G. A. (1996): Capital Flows and Macroeconomic Management: Tequila Lessons. International Journal of Finance and Economics 1, no. 3: 207-23.

Calvo, G. A., and Reinhart, C. M. (2000): Fear of Floating. NBER Working Paper N. 7993

Campbell, J. Y. (1996): Understanding risk and return. Journal of Political Economy 104, 298-345.

Campbell J. Y., Lo A. W., and MacKinlay A. C. (1997): The Econometrics of Financial Markets. New Jersey: Princeton University Press.

Campbell J. Y. and Viceira L. M. (1998): Who Should Buy Long-Term Bonds? unpublished manuscript.

Chamon, M., Manasse, P., and Prati, A. (2007): Can We Predict the Next Capital Account Crisis?. IMF Staff Papers, Palgrave Macmillan Journals, vol. 54(2), pages 270-305, June.

Cheung, y-w., AND Ito, H. (2007): A Cross-Country Empirical Analysis of International Reserves. memo 
Corsetti, G. and Roubini, N. (1991): Fiscal Deficits, Public Debt and Government Solvency: Evidence from OECD Countries. Journal of the Japanese and International Economics, 5, pp. 354-380.

Day, P. and Choi, H. W. (2004): Asian Central Banks Consider Alternative to Big Dollar Holdings. Wall Street Journal, February 5, 2004.

De Beaufort-Wijnholds, J. Onno, and Arend Kapteyn. (2001): Reserve Adequacy in Emerging Market Economies. Working Paper 01/143. Washington: International Monetary Fund (September).

Duffie D. (1986): Stochastic Equilibria: Existence, Spanning Number, and the No Expected Financial Gain From Trade Hypothesis. Econometrica, 54. 1161-1183.

Durdu C. B., Mendoza E. G., and Terrones M. E. (2007): Precautionary Demand for Foreign Assets in Sudden Stop Economies: An Assessment of the New Merchantilism. IMF Working Paper WP/07/146.

Edwards, S. (1985): On the Interest-Rate Elasticity of the Demand for International Reserves: Some Evidence from Developing Countries. Journal of International Money and Finance 4(2): 28795.

Fisher, S. (2001): Opening Remarks. IMF/World Bank International Reserves: Policy Issues Forum, Washington DC, 28 April.

Flood, R. and Marion N. (2002): Holding International Reserves In an Era of High Capital Mobility. IMF Working Paper 02/62. IMF, Washington DC.

Frenkel, J. and Jovanovic B. (1981): Optimal International Reserves: A Stochastic Framework. Economic Journal 91, 507-514.

Garcia, P. S., and Soto, C. (2004): Large Hoarding of International Reserves: Are they worth it? manuscript, Bank of Chile.

Glick, R. and Rogoff, K. S. (1995): Global versus Country-Specific Productivity Shocks and the Current Account. Journal of Monetary Economics, pp 59-192.

Gosselin M-A., and Parent N. (2005): An Empirical Analysis of Foreign Exchange Reserves in Emerging Asia. Bank of Canada Working Paper 2005-38.

Greenspan, A. (1999): Currency Reserves and Debt. Remarks by Chairman Alan Greenspan before the World Bank Conference on Recent Trends in Reserve Management, Washington, 29 April.

Hamilton J. D. (1994): Time Series Analysis. Princeton University Press. Princeton, New Jersy.

Hausmann, R., U. Panizza and R. Rigobon (2006): The long-run volatility puzzle of the real exchange rate. Journal of international Money and Finance 25: 93-134.

Hausmann, R., Panizza, U. and Stein E. (2000): Why Do Countries Float the Way They Float? memo, Inter-American development Bank. 
Heller, R.H. and M.S. Khan. (1978): The Demand for International Reserves Under Fixed and Floating Exchange Rates. International Monetary Fund Staff Papers 25(4): pp. 623-49.

IDB (Inter American Development Bank) (1995). Economic and Social Progress in Latin America, Part 2: Overcoming Volatility.

International Monetary Fund, IMF (2003): Are Foreign Exchange Reserves in Asia Too High?. World Economic Outlook (September): 64-77.

International Energy Agency, Annual Report 2006.

Jeanne O. (2007): International Reserves in Emerging Market Countries: Too Much of a Good Thing? Brookings Papers on Economic Activity (1).

Krugman, P. (1979): A model of BOP crises. Journal of Money, Credit, and Banking 11: 311-325.

Landell-Mills, J.M. (1989): The Demand for International Reserves and their Opportunity Cost. International Monetary Fund Staff Papers 36(3): 10732.

Lane, P.R. and Burke D. (2001): The Empirics of Foreign Reserves. Open Economy Review 12(4): 42334.

Lee, J. (2005): Insurance Value of International Reserves, an Option Pricing Approach. International Monetary Fund, Washington.

Leiderman, L. and Razin, A (1991): Determinants of External Imbalances: The Role of Taxes, Government Spending, and Productivity. Journal of the Japanese and International Economics, 5, pp. 421-450.

Lizondo, J. and Mathieson D. (1987): The Stability of the Demand for International Reserves. Journal of International Money and Finance 6(3): 251-82.

Lloyd-Ellis, H. and Zhu X. (2001): Fiscal shocks and fiscal risk management. Journal of Monetary economics 48. 309-338.

Lloyd-Ellis, H. and Zhu X. (2006): Using Financial Market Information to Enhance Canadian Fiscal Policy. Public Finance and Management, vol. 6 (2).151-185.

Milesi-Ferretti, G. M. and Razin A. (1996): Current Account Sustainability. Princeton Studies in International Finance, No. 81.

Mody, A., and Taylor, M. P. (2002): International Capital Crunches: The Time-Varying Role of Informational Asymmetries. IMF Working Paper 02/43.

Pringle, R. and Carver, N., eds. (2005) RBS Reserve Management Trends. London: Central Banking Publications.

Razin, A. (1993): The Dynamic-Optimizing Approach of Current Account: Theory and Evidence in Peter 
B. Kenen, ed. Understanding Interdependence : The macroeconomics of the Open Economy, Princeton, N.J., Princeton University Press. pp. 169-198.

Rothenberg, A. D. and Warnock F. E. (2006): Sudden flight and true sudden stops. NBER Working Paper 12726.

Sachs, J. D., Tornell, A., and Velasco, A. (1996): The Mexican peso crisis: Sudden death or death foretold? Journal of International Economics, 41, pp.265-283.

Sørensen, P. B., and Whitta-Jacobsen, H. J. (2005): Introducing Advanced Macroeconomics: growth \& Business Cycles. ed. Mc Graw Hill. Chapter 19, pp.559-60, and chapter 20, pp.611-12.

Taylor, J. B. (1993): Discretion Versus Policy Rules in Practice. Carnegie-Rochester Conference Series on Public Policy, 39, pp. 195-214.

Tobin, J. (1956): The Interest Elasticity of Transactions Demand for Cash. Review of Economics and Statistics, Vol. 38 No. 3, (August), 241-70.

Xinhua News Agency (2004): China Sets No Target for Forex Reserve. http://news.xinhuanet.com/english/2004-03/07/content_1350147.htm 


\section{Appendix}

\section{A. VAR Estimates}

Table 3: VAR Estimates

\begin{tabular}{|l||c|c|c|c|c|c|}
\hline & LCOP(-1) & LUSMCO $(-1)$ & DIV(-1) & TBILL(-1) & LONG(-1) & VWR(-1) \\
\hline \hline LCOP & .92 & .14 & .22 & .11 & .12 & -.18 \\
& $(.04)$ & $(.08)$ & $(.29)$ & $(1.12)$ & $(1.62)$ & .17 \\
\hline \multirow{2}{*}{ LUSMCO } & .04 & .82 & -.23 & .58 & -1.58 & -.15 \\
& $(.03)$ & $(.06)$ & $(.23)$ & $(.87)$ & $(1.25)$ & $(.13)$ \\
\hline \multirow{2}{*}{ DIV } & .01 & -.04 & .63 & -.40 & 1.15 & -.009 \\
& $(.01)$ & $(.02)$ & $(.07)$ & $(.28)$ & $(.40)$ & $(.04)$ \\
\hline TBILL & .001 & -.002 & .005 & .95 & -.05 & .012 \\
& $(.002)$ & $(.004)$ & $(.01)$ & $(.05)$ & $(.07)$ & $. .008)$ \\
\hline LONG & .001 & -.007 & -.006 & .07 & .83 & .008 \\
& $(.002)$ & $(.003)$ & $(.011)$ & $(.04)$ & $(.06)$ & $(.007)$ \\
\hline VWR & -.026 & .09 & .48 & -.18 & -.35 & -.17 \\
& $(.024)$ & $(.05)$ & $(.18)$ & $(.67)$ & $(.97)$ & $(.10)$ \\
\hline \hline
\end{tabular}

\section{B. Data}

\section{B.1. Traditional variables}

GDP: gross domestic product is taken from the national accounts of the BOP (Billions of Pesos), IFS series code 27399B.CZF... It is converted into U.S. dollars using the end of period pesos per U.S. dollars rate taken from IFS series code 273..WE.ZF...

EXRV: 12 months moving average standard deviation of the end of period Pesos per U.S.dollars rate.

EXPV: exports volatility is measured as 10 quarters backward moving standard deviation of exports receipts. Exports receipts are the Exports of Goods and Services (billions of Pesos) taken from national accounts of the BOP, IFS series code 27390C.CZF...

$\triangle L I M P$ : change in the imports to GDP ratio. Imports of Goods and Services are taken form national accounts of the BOP, IFS series code $27398 \mathrm{C} . \mathrm{CZF} \ldots$

$\Delta M 2$ : change in broad money to GDP ratio. M2 is taken from IFS, series code $27359 \mathrm{MB} . Z \mathrm{~F} \ldots$ It is measured in Millions of Pesos.

FO: financial openness, which is calculated as the ratio of Capital flows to GDP. Capital flows are measured by the financial account of the BOP, series code 27378BJDZF....

OPPCOST: the opportunity cost of holding reserves is calculated as the difference between the Mexican deposit rate, taken form the IFS, series code $27360 \mathrm{~L} . . Z \mathrm{ZF} . .$. and the U.S. treasury bill rate series code $11160 \mathrm{C} . \mathrm{ZF} \ldots$. 


\section{B.2. Asset Returns}

VWR is the index of value-weighted returns on the NYSE taken from the CRSP tape. DIV is the dividend yield on the NYSE from the CRSP tape. LONG is the nominal interest rate on 10 year U.S. government bonds. TBILL is the nominal 3-month U.S. treasury bill rate.

\section{B.3. Other variables}

$\triangle L C O P$ : growth rate of the average crude oil (nominal) price (U.S.\$/barrel). IFS series code 00176AAZZF... $\triangle L U S M C O$ : growth rate of quarterly totals of U.S. imports of crude oil from Mexico. 1000barrels/day. Taken from Economagic.com http://www.economagic.com/em-cgi/data.exe/tmp/130-15-74-172!20081021103306

\section{B.4. Trade Balance}

Reserves: foreign exchange holdings, measured in U.S. dollars. IFS series code 273.1D.DZF...

Income Transfers: it is calculated as the difference between Income Credits, IFS series code 27378AGDZF..., and Income Debt, IFS series code 27378AHDZF...

\section{Net Liability Position}

Only few observations of the international investment position are available in the IFS database. For Mexico, there are 6 annual observations, 2001 through 2006. To infer the quarterly data we use some identities from the BOP. To outline our approach we first need to define our variables. Define,

- $L_{t}$ : Net Liability Position in period $t$,

- $R_{t}$ : Stock of International Reserves the country holds in period $t$,

- $I T_{t}$ : Net Income Transfers in period $t$. It is equal to Income Credit - Income Debt.

- $T B_{t}$ : Trade balance in period $t$.

From the balance of payment equations we have

$$
R_{t+1}-L_{t+1}=R_{t}-L_{t}+I T_{t}+T B_{t}
$$

or

$$
L_{t+1}=\Delta R_{t}+L_{t}-I T_{t}-T B_{t}
$$

where $\Delta R_{t}=R_{t+1}-R_{t}$. Since we have only few observations of $L_{t}$ which they are annual (end of period) and refer to the last 6 years only we infer the quarterly data starting from the last observation, i.e. 2006, which is also the observation relative to the last quarter of the year 2006, i.e. 2006:4 and then work our way backward using the quarterly flow variables we have $\left(\Delta R_{t}, I T_{t}\right.$, and $\left.T B_{t}\right)$. That is,

$$
L_{t}=L_{t+1}-\Delta R_{t}+I T_{t}+T B_{t}
$$

\section{Calibration of the Two-Factor Asset pricing Model}

From (14), (18), and (20), the moment condition of the risk premium can be written as follows:

$$
\exp \left(E_{t}\left[R_{t+1}^{m}\right]-r_{t}^{T B I L L}+\frac{1}{2} \sigma_{6, u}^{2}-\rho_{6} \sigma_{6, u}^{2}-\rho_{4} \sigma_{46, u}\right)=1
$$


or,

$$
E_{t}\left[R_{t+1}^{m}\right]-r_{t}^{T B I L L}+\frac{1}{2} \sigma_{6, u}^{2}-\rho_{6} \sigma_{6, u}^{2}-\rho_{4} \sigma_{46, u}=0 .
$$

Taking unconditional expectations of the left hand side of the equation yields

$$
E_{t}\left[R_{t}^{m}-r_{t}^{T B I L L}\right]+\frac{1}{2} \sigma_{6, u}^{2}-\rho_{6} \sigma_{6, u}^{2}-\rho_{4} \sigma_{46, u}=0 .
$$

Replacing the theoretical moments with sample moments, we have

$$
\frac{1}{T} \sum_{t=1}^{T}\left(R_{t}^{m}-r_{t}^{T B I L L}\right)+\frac{1}{2} \sigma_{6, u}^{2}-\rho_{6} \sigma_{6, u}^{2}-\rho_{4} \sigma_{46, u}=0
$$

Using (14) and (15) we have

$$
E_{t}\left[\frac{M_{t+2 j}}{M_{t}}\right]=\exp \left(-\left(E\left[r_{t}^{T B I L L}\right]+\frac{1}{2} \sigma_{\omega}^{2}\right) 2 j-m_{z}(t, 2 j)+\frac{1}{2} V_{z z}(t, 2 j)\right) .
$$

where

$$
\begin{aligned}
m_{z}(t, 2 j) & =E_{t}\left[-\left(\ln M_{t+2 j}-\ln M_{t}\right)-2 \varpi j\right] \\
V_{z z}(t, 2 j) & =E_{t}\left[\left(-\left(\ln M_{t+2 j}-\ln M_{t}\right)-2 \varpi j-m_{z}(t, 2 j)\right)^{2}\right]
\end{aligned}
$$

So, the moment condition (15) can be written as

$$
\begin{gathered}
1=\frac{1}{2}\left[\sum_{j=1}^{20} \exp \left(-\left(E\left[r_{t}^{T B I L L}\right]+\frac{1}{2} \sigma_{\omega}^{2}\right) 2 j-m_{z}(t, 2 j)+\frac{1}{2} V_{z z}(t, 2 j)\right)\right] r_{t}^{L O N G} \\
+\exp \left(-\left(E\left[r_{t}^{T B I L L}\right]+\frac{1}{2} \sigma_{\omega}^{2}\right) 40-m_{z}(t, 40)+\frac{1}{2} V_{z z}(t, 40)\right)
\end{gathered}
$$

Taking the sample average of the right hand side of this equation yields

$$
\begin{gathered}
1=\frac{1}{2} \sum_{j=1}^{20}\left[\exp \left(-\left(E\left[r_{t}^{T B I L L}\right]+\frac{1}{2} \sigma_{\omega}^{2}\right) 2 j-m_{z}(t, 2 j)+\frac{1}{2} V_{z z}(t, 2 j)\right)\right] r_{t}^{L O N G} \\
+\exp \left(-\left(E\left[r_{t}^{T B I L L}\right]+\frac{1}{2} \sigma_{\omega}^{2}\right) 40-m_{z}(t, 40)+\frac{1}{2} V_{z z}(t, 40)\right)
\end{gathered}
$$

The parameters $\rho_{4}$ and $\rho_{6}$ are chosen so that they are the solutions to the equations (26) and (29). This is done by using (26) to express $\rho_{6}$ as a linear function of $\rho_{4}$ and substituting into equation (29). We then numerically look for the value $\rho_{4}$ that solves equation (29).

\section{Details Related to Calculation of the Present Value}

To compute the present value of Mexico net income we proceed as follow: for each date, we computed the change in reserves, $\Delta R_{t}=R_{t}-R_{t-1}$, the change in net liabilities position, $\Delta L_{t}=L_{t}-L_{t-1}$, and the income transfers, $I T_{t}$ and then we discount at rate $M_{t} / M_{t-1}$. 
We need to calculate present value of nominal cash-flows of the following form:

$$
B(t, j)=\frac{1}{M_{t}} E_{t}\left[M_{t+j}(\underbrace{\left(R_{t+j}-R_{t+j-1}\right)}_{\Delta R_{t+j}}-\underbrace{\left(L_{t+j}-L_{t+j-1}\right)}_{\Delta L_{t+j}}-I T_{t+j})\right]
$$

Let $Z(t, j)=-\ln \left(M_{t+j}\right)$. Then ${ }^{22}$

$$
Z(t, j)=Z(t, j-1)+\mathbf{b}^{T} X_{t+j-1}+w_{t+j},
$$

where $Z(t, 0)=-\ln M_{t}$ and $\omega_{t}$ is i.i.d, and $\omega_{t} \sim N\left(0, \sigma_{\omega}^{2}\right)$. It follows that

$$
B(t, j)=\frac{1}{M_{t}} E_{t}\left[e^{-Z(t, j)}\left(\Delta R_{t+j}-\Delta L_{t+j}-I T_{t+j}\right)\right]
$$

or

$$
B(t, j)=\frac{1}{M_{t}}\{\underbrace{E_{t}\left[e^{-Z(t, j)} \Delta R_{t+j}\right]}_{(I)}-\underbrace{E_{t}\left[e^{-Z(t, j)} \Delta L_{t+j}\right]}_{(I I)}-\underbrace{E_{t}\left[e^{-Z(t, j)} I T_{t+j}\right]}_{(I I I)}\}
$$

To calculate this present value we need to calculate its three components, (I), (II), and (III). Recall that in section 2 we derived the processes driving $R_{t}, L_{t}$, and $I T_{t}$. Using section 2 , we have

$$
R_{t}=Y_{t} e^{\beta_{0}} e^{\beta^{T} X_{t}+\epsilon_{t}}=e^{\beta_{0}} e^{\beta^{T} X_{t}+\epsilon_{t}} Y_{0} \prod_{s=0}^{t}\left(1+g_{s}\right)
$$

where $Y_{0}$ stands for the output in $0, g_{s}$ is the growth rate of output between periods $s$ and $s-1$, and $\prod_{s=0}^{t}\left(1+g_{s}\right)$ is the output growth between periods 0 and $t$. It follows that

$$
\Delta R_{t}=Y_{0} e^{\beta_{0}}\left[e^{\beta^{T} X_{t}+\epsilon_{t}} \prod_{s=0}^{t}\left(1+g_{s}\right)-e^{\beta^{T} X_{t-1}+\epsilon_{t-1}} \prod_{s=0}^{t-1}\left(1+g_{s}\right)\right]
$$

Similarly, we have

$$
L_{t}=Y_{t} e^{\alpha_{0}+\alpha^{T} X_{t}+\mu_{t}}=e^{\alpha_{0}+\alpha^{T} X_{t}+\mu_{t}} Y_{0} \prod_{s=0}^{t}\left(1+g_{s}\right)
$$

it follows that

$$
\Delta L_{t}=Y_{0} e^{\alpha_{0}}\left[e^{\alpha^{T} X_{t}+\mu_{t}} \prod_{s=0}^{t}\left(1+g_{s}\right)-e^{\alpha^{T} X_{t-1}+\mu_{t-1}} \prod_{s=0}^{t-1}\left(1+g_{s}\right)\right]
$$

${ }^{22}$ This is the general form. As outlined in the paper, in our case we use the following specification

$$
-\ln \left(\frac{M_{t}}{M_{t-1}}\right)=r_{t-1}+\frac{1}{2} \sigma^{2}+\omega_{t}
$$

That is $\mathbf{b}^{T}=(0,0,1 / 4,0)$. Which can be rewritten this as follow

$$
-\log M_{t}=-\ln M_{t-1}+r_{t-1}+\frac{1}{2} \sigma^{2}+\omega_{t}
$$


The income transfers, $I T_{t}$, process is,

$$
I T_{t}=-Y_{t} e^{\gamma_{0}+\gamma^{T} X_{t}+\varsigma_{t}}=-Y_{0} e^{\gamma_{0}} e^{\gamma^{T} X_{t}+\varsigma_{t}} \prod_{s=0}^{t}\left(1+g_{s}\right)
$$

Note that $1+g_{t}$ can be approximated by $e^{g_{t}}$; that is,

$$
1+g_{t} \approx e^{g_{t}}
$$

We further assume that the growth rate of GDP evolves according to the following process

$$
g_{t}=\bar{g}-\frac{1}{2} \sigma_{\eta}^{2}+\eta_{t}
$$

where $\bar{g}$ is a constant and $\eta_{t}$ is i.i.d, and $\eta_{t} \sim N\left(0, \sigma_{\eta}^{2}\right)$.

Let

$$
\Gamma(t, j)=\prod_{s=0}^{t+j} e^{g_{s}}
$$

Using (31), (35), (37), and (39)-(41) we can rewrite (I), (II), and (III) as follow

$$
\begin{aligned}
(I): E_{t}\left[e^{-Z(t, j)} \Delta R_{t+j}\right]= & Y_{0} e^{\beta_{0}} E_{0}\left[e ^ { - Z ( t , j ) } \left(e^{\beta^{T} X_{t+j}+\epsilon_{t+j}} \Gamma(t, j)\right.\right. \\
& \left.\left.-e^{\beta^{T} X_{t+j-1}+\epsilon_{t+j-1}} \Gamma(t, j-1)\right)\right]
\end{aligned}
$$

or,

$$
\begin{aligned}
& (I): E_{t}\left[e^{-Z(t, j)} \Delta R_{t+j}\right]=\quad Y_{0} e^{\beta_{0}}\{\underbrace{E_{0}\left[e^{-Z(t, j)+\beta^{T} X_{t+j}+\epsilon_{t+j}} \Gamma(t, j)\right]}_{(I a)} \\
& -\underbrace{E_{0}\left[e^{-Z(t, j)+\beta^{T} X_{t+j-1}+\epsilon_{t+j-1}} \Gamma(t, j-1)\right]}_{(I b)}\} \\
& (I I): E_{t}\left[e^{-Z(t, j)} \Delta L_{t+j}\right]=\quad Y_{0} e^{\alpha_{0}}\{\underbrace{E_{0}\left[e^{-Z(t, j)+\alpha^{T} X_{t+j}+\mu_{t+j}} \Gamma(t, j)\right]}_{(I I a)} \\
& -\underbrace{E_{0}\left[e^{-Z(t, j)+\alpha^{T} X_{t+j-1}+\mu_{t+j-1}} \Gamma(t, j-1)\right]}_{(I I b)}\} \\
& (I I I): E_{t}\left[e^{-Z(t, j)} I T_{t+j}\right]=-Y_{0} e^{\gamma_{0}} \underbrace{E_{0}\left[e^{-Z(t, j)+\gamma^{T} X_{t+j}+\varsigma_{t+j}} \Gamma(t, j)\right]}_{(\text {III })}
\end{aligned}
$$


So,

$$
B(t, j)=\frac{1}{M_{t}}[(I)-(I I)-(I I I)]=\frac{1}{M_{t}} Y_{0}\left[e^{\beta_{0}}[(I a)-(I b)]-e^{\alpha_{0}}[(I I a)-(I I b)]+e^{\gamma_{0}}(I I I a)\right]
$$

The next exercise is to calculate (Ia), (Ib), (IIa), (IIb), and (IIIa) in or der to get the present value of cash-flows.

$$
\begin{aligned}
(I a): E_{0}\left[e^{-Z(t, j)+\beta^{T} X_{t+j}+\epsilon_{t+j}} \Gamma(t, j)\right]= & E_{0}\left[e^{-Z(t, j)+\beta^{T} X_{t+j}+\epsilon_{t+j}}\right] E_{0}[\Gamma(t, j)] \\
& +C O V\left(e^{-Z(t, j)+\beta^{T} X_{t+j}+\epsilon_{t+j}}, \Gamma(t, j)\right)
\end{aligned}
$$

Note that $\operatorname{COV}\left(e^{-Z(t, j)+\beta^{T} X_{t+j}+\epsilon_{t+j}}, \Gamma(t, j)\right)=0$. Recall that

$$
\Gamma(t, j)=\prod_{s=0}^{t+j} e^{g_{s}},
$$

and using the process driving the growth rate described above, (38), we have that $E\left[e^{g_{s}}\right]=e^{\bar{g}}$, and

$$
\begin{gathered}
E[\Gamma(t, j)]=e^{\bar{g}(t+j)} \\
E_{0}\left[e^{-Z(t, j)+\beta X_{t+j}+\epsilon_{t+j}}\right]=e^{-m_{z}(t, j)+\beta^{T} m_{x}(t, j)+E\left[\epsilon_{t+j}\right]+\frac{1}{2} V\left(-Z(t, j)+\beta X_{t+j}+\epsilon_{t+j}\right)}
\end{gathered}
$$

where $m_{z}(t, j)=E[Z(t, j)]$ and $m_{x}(t, j)=E\left[X_{t+j}\right]$. Note that $E\left[\epsilon_{t+j}\right]=0$. So,

$$
E_{0}\left[e^{-Z(t, j)+\beta X_{t+j}+\epsilon_{t+j}}\right]=e^{-m_{z}(t, j)+\beta^{T} m_{x}(t, j)+\frac{1}{2} V\left(-Z(t, j)+\beta^{T} X_{t+j}+\epsilon_{t+j}\right)}
$$

Let $V\left(-Z(t, j)+\beta X_{t+j}+\epsilon_{t+j}\right)=V_{\beta, \epsilon}(j)$. Then,

$$
\begin{aligned}
& V_{\beta, \epsilon}(j)=V\left(-Z(t, j)+X_{t+j} \beta\right)+V\left(\epsilon_{t+j}\right)+2 C O V\left(-Z(t, j)+X_{t+j} \beta, \epsilon_{t+j}\right) \\
& =V(Z(t, j))+\beta^{T} V\left(X_{t+j}\right) \beta+2 C O V\left(-Z(t, j), X_{t+j} \beta\right)+V\left(\epsilon_{t+j}\right) \\
& +2 \operatorname{COV}\left(-Z(t, j)+\beta X_{t+j}, \epsilon_{t+j}\right) \\
& =V(Z(t, j))+\beta^{T} V\left(X_{t+j}\right) \beta-2 C O V\left(Z(t, j), X_{t+j}\right) \beta+V\left(\epsilon_{t+j}\right) \\
& +2\left[-\operatorname{COV}\left(Z(t, j), \epsilon_{t+j}\right)+\beta^{T} \operatorname{COV}\left(X_{t+j}, \epsilon_{t+j}\right)\right]
\end{aligned}
$$

We have that $\operatorname{COV}\left(Z(t, j), \epsilon_{t+j}\right)=0$ and $\operatorname{COV}\left(X_{t+j}, \epsilon_{t+j}\right)=0$. So it follows that

$$
V_{\beta, \epsilon}(j)=V(Z(t, j))+\beta^{T} V\left(X_{t+j}\right) \beta-2 \beta^{T} C O V\left(X_{t+j}, Z(t, j)\right)^{T}+V\left(\epsilon_{t+j}\right)
$$

Let $V_{x x}(j)=V\left(X_{t+j}\right), V_{z z}(j)=V(Z(t, j)), V_{x z}(j)=C O V\left(Z(t, j), X_{t+j}\right)$. 
Then (50) can be written as

$$
V_{\beta, \epsilon}(j)=V_{z z}(j)+\beta^{T} V_{x x}(j) \beta-2 V_{x z}(j) \beta+\sigma_{\epsilon}^{2}
$$

To iterate on this moment we need to calculate $V_{x x}(j), V_{z z}(j)$, and $V_{x z}(j)$. These moments can be calculated recursively as follows:

$$
\begin{gathered}
\mathbf{m}_{x}(t, j)=\mathbf{A} \mathbf{m}_{x}(t, j-1) \\
\mathbf{m}_{z}(t, j)=\mathbf{m}_{z}(t, j-1)+\mathbf{b}^{T} \mathbf{m}_{x}(t, j-1) \\
\mathbf{V}_{x x}(j)=\mathbf{A} \mathbf{V}_{x x}(j-1) \mathbf{A}^{T}+\Sigma \\
\mathbf{V}_{x z}(j)=\mathbf{A} \mathbf{V}_{x z}(j-1)+\mathbf{A} \mathbf{V}_{x x}(j-1) \mathbf{b}+\mathbf{v} \\
\mathbf{V}_{z z}(j)=\mathbf{V}_{z z}(j-1)+2 \mathbf{b}^{T} \mathbf{V}_{x z}(j-1)+\mathbf{b}^{T} \mathbf{V}_{x x}(j-1) \mathbf{b}+\sigma_{\omega}^{2}
\end{gathered}
$$

where $\mathbf{m}_{z}(t, 1)=\mathbf{b}^{T} \mathbf{X}_{t}-\ln M_{t}, \mathbf{m}_{x}(t, 1)=\mathbf{A} \mathbf{X}_{t}, \mathbf{V}_{x x}(1)=\Sigma, \mathbf{V}_{x z}=\mathbf{v}$, and $V_{z z}=\sigma_{\omega}^{2}$.

We can rewrite (48) as follows

$$
E_{0}\left[e^{-Z(t, j)+\beta X_{t+j}+\epsilon_{t+j}}\right]=e^{-m_{z}(t, j)+\beta^{T} m_{x}(t, j)+\frac{1}{2} V_{\beta, \epsilon}(j)}
$$

Using (47) and (57) we have that

$$
(I a)=\exp \left\{-m_{z}(t, j)+\beta^{T} m_{x}(t, j)+\frac{1}{2} V_{\beta, \epsilon}(j)+\bar{g}(t+j)\right\}
$$

Similar calculations lead to the derivation of $(I b)$,

$$
(I b)=\exp \left\{-m_{z}(t, j)+\beta^{T} m_{x}(t, j-1)+\frac{1}{2} Q_{\beta, \epsilon}(j-1)+\bar{g}(t+j-1)\right\}
$$

where,

$$
Q_{\beta, \epsilon}=\mathbf{V}_{z z}(j)+\beta^{T} V_{x x}(j-1) \beta-2 \beta^{T}\left[\mathbf{V}_{x z}(j-1)+\mathbf{V}_{x x}(j-1) \mathbf{b}\right]+\sigma_{\epsilon}^{2}
$$

Following the same steps we can calculate, $(I I a),(I I b)$, and $(I I I a)$

$$
\begin{gathered}
(I I a)=\exp \left\{-m_{z}(t, j)+\alpha^{T} m_{x}(t, j)+\frac{1}{2} V_{\alpha, \mu}(j)+\bar{g}(t+j)\right\} \\
(I I b)=\exp \left\{-m_{z}(t, j)+\alpha^{T} m_{x}(t, j-1)+\frac{1}{2} Q_{\alpha, \mu}(j)+\bar{g}(t+j-1)\right\} \\
(I I I a)=\exp \left\{-m_{z}(t, j)+\gamma^{T} m_{x}(t, j)+\frac{1}{2} V_{\gamma, \varsigma}(j)+\bar{g}(t+j)\right\}
\end{gathered}
$$

where,

$$
\begin{gathered}
V_{\alpha, \mu}(j)=V_{z z}(j)+\alpha^{T} V_{x x}(j) \alpha-2 V_{x z}(j) \alpha+\sigma_{\mu}^{2}, \\
Q_{\alpha, \mu}=\mathbf{V}_{z z}(j)+\alpha^{T} V_{x x}(j-1) \alpha-2 \alpha^{T}\left[\mathbf{V}_{x z}(j-1)+\mathbf{V}_{x x}(j-1) \mathbf{b}\right]+\sigma_{\mu}^{2}, \\
V_{\gamma, \varsigma}(j)=V_{z z}(j)+\gamma^{T} V_{x x}(j) \gamma-2 V_{x z}(j) \gamma+\sigma_{\varsigma}^{2}
\end{gathered}
$$


Recall from (45) we have

$$
B(t, j)=\frac{1}{M_{t}}[(I)-(I I)-(I I I)]=\frac{1}{M_{t}} Y_{0}\left[e^{\beta_{0}}[(I a)-(I b)]-e^{\alpha_{0}}[(I I a)-(I I b)]+e^{\gamma_{0}}(I I I a)\right]
$$

So, the present value of the trade balance (i.e., country's future net income) is equal to

$$
V(T B)=\frac{1}{M_{t}} \sum_{j=1}^{\infty} B(t, j)
$$

